$$
D R-1269-6
$$

\title{
Ultrasonic Longitudinal Wave Velocity in Carbon-Carbon Pitch and Pitch/M2 Shape Stable Nosetip Material from $70^{\circ} \mathrm{F}$ to $5400^{\circ} \mathrm{F}$
}

\author{
J. H. Gieske
}

Prepared by

Sandia National Laboratories

Albuquerque, New Mexico 87185 and Livermore, California 94550

for the United States Department of Energy

under Contract DE-AC04-76DP00789 
Issued by Sandia National Laboratories, operated for the United States Department of Energy by Sandia Corporation

NOTICE: This report was prepared as an account of work sponsored by an agency of the United States Government Neither the United States Government nor any agency thereof, nor any of their employees, nor any of their contractors, subcontractors, or their employees, makes any warranty, ex press or implied, or assumes any legal liability or responsibility for the accuracy, completeness, or usefulness of any information, apparatus, prod uct, or process disclosed, or represents that its use would not infringe privately owned rights Reference herein to any specific commercial product, process, or service by trade name, trademark, manufacturer, or otherwise, does not necessarily constitute or imply its endorsement, recommendation,
or favoring by the United States Government, any agency thereof or any of their contractors or subcontractors The views and opınıons expressed herein do not necessarily state or reflect those of the United States Government, any agency thereof or any of their contractors or subcontractors

Printed in the United States of America Avallable from

National Technical Informatıon Service

US Department of Commerce

5285 Port Royal Road

Springfield, VA 22161

NTIS price codes

Printed copy A04

Microfiche copy A01 


\section{DISCLAIMER}

This report was prepared as an account of work sponsored by an agency of the United States Government. Neither the United States Government nor any agency Thereof, nor any of their employees, makes any warranty, express or implied, or assumes any legal liability or responsibility for the accuracy, completeness, or usefulness of any information, apparatus, product, or process disclosed, or represents that its use would not infringe privately owned rights. Reference herein to any specific commercial product, process, or service by trade name, trademark, manufacturer, or otherwise does not necessarily constitute or imply its endorsement, recommendation, or favoring by the United States Government or any agency thereof. The views and opinions of authors expressed herein do not necessarily state or reflect those of the United States Government or any agency thereof. 


\section{DISCLAIMER}

Portions of this document may be illegible in electronic image products. Images are produced from the best available original document. 
SAND $--85-0853$

DE85 017330

UC-25

SAND85-0853

Ultrasonic Longitudinal Wave Velocity in Carbon-Carbon Pitch and Pitch/M2 Shape stable Nosetip Material from $70^{\circ} \mathrm{F}$ to $5400^{\circ} \mathrm{F}$ (U)

J. H. Gieske

Nondestructive Testing Technology Division

Sandia National Laboratories

Albuquerque, New Mexico 87185

\begin{abstract}
A pulse echo method was used in two notched rods of carboncarbon Pitch material and one rod of Pitch/M2 shape stable nosetip material to measure the temperature dependence of the longitudinal wave velocity from room temperature to $5400^{\circ} \mathrm{F}$. The velocity was constant to within $2 \%$ of the room temperature value for the Pitch parent material throughout the temperature range. For the Pitch/M2 material, the velocity increased to a maximum of $10 \%$ at $4000 \% \mathrm{~F}$ and then decreased rapidly. Room temperature velocities in the principal directions of the composite are also given for the two pitch rods, which showed a $15 \%$ decrease in velocity near the ends of both rods and near the side of one rod.
\end{abstract}

\title{
MASTER
}




\section{CONTENTS}

Page

Introduction

$7-8$

Experimental Methods

Preparation of the Test specimens and

Recorded Temperature Data

Temperature Test Results

Material Property Variations of ROD \#1 and ROD \#3

Measurement Errors

Summary and conclusions

References

\section{FIGURES}

1. Schematic Diagram of Electronics to Record Pulse Echo Waveforms with the Analog system and the Digital system.

2. Digitized Waveforms of Notch Echo and End Echo Versus Temperature for the Low Temperature Test \#2 of ROD \# 1 .

3. Digitized Waveforms of Notch Echo and End Echo Versus Temperature for the Low Temperature Test of ROD \#2.

4. Digitized Waveforms of Notch Echo and End Echo Versus Temperature for the High Temperature Test of ROD \#2.

5. Digitized Waveforms of Notch Echo and End Echo Versus Temperature for the Low Temperature Test of ROD \#3.

6. Digitized Waveforms of Notch Echo and End Echo Versus Temperature for the High Temperature Test of ROD \#3. 
7. Normalized Longitudinal Velocity Versus

Temperature for ROD \#1, VO = $8.796 \mathrm{~mm} /$ Microsecond.

8. Normalized Longitudinal Velocity Versus

Temperature for ROD \#2, VO $=4.187 \mathrm{~mm} /$ Microsecond.

9. Normalized Longitudinal Velocity Versus

Temperature for ROD \#3, VO $=9.63 \mathrm{~mm} / \mathrm{Microsecond}$.

10. Through Transmission Waveforms and Delay Times

in the X-Direction of ROD \#l at Axial Locations Along

the ROD. X Dimension Equals 0.625 Inches.

11. Through Transmission Waveforms and Delay Times

in the $X-D i r e c t i o n$ of ROD \#3 at Axial Locations Along the ROD. $X$ Dimension Equals 0.583 inches.

12. Variation of Longitudinal Velocity in the $x-$

Direction of the Composite Along the Length of ROD

$\# 1$ and ROD \#3.

13. Longitudinal Velocity Determinations at Various Locations in the $\mathrm{Y}-\mathrm{Direction}$ and $\mathrm{Z}-\mathrm{Direction}$ for ROD \# 1 and ROD \#3.

\section{TABLES}

I. Longitudinal Velocity Temperature Data for

ROD \#I Pitch Parent Material.

II. Longitudinal Velocity Temperature Data for ROD \#2 Pitch/M2 Material.

III. Longitudinal Velocity Temperature Data for

ROD \#3 Pitch Parent Material

Appendix A

Appendix B

$47-50$

Appendix C 
ULTRASONIC LONGITUDINAL WAVE VELOCITY IN CARBON-CARBON PITCH AND PITCH/M2 SHAPE STABLE NOSETIP MATERIAL

FROM $70^{\circ} \mathrm{F}$ TO $5400^{\circ} \mathrm{F}$

Introduction

This work was requested by Lockheed Missiles \& Space Company, Inc., in order to provide temperature dependent ultrasonic velocity data needed in use of the Ultrasonic Ablation Detector (UAD). The UAD is to be used to measure inflight recession of the Shape stable Nosetip (SSNT) on the DASO and the MK5 Flight Vehicle. The UAD provides measurements of recession at a given instant by recording the round trip delay time of an ultrasonic wave to traverse the length of the nosetip. Current nosetip length at that instant is determined by multiplying the known ultrasonic wave velocity by half the round trip delay time. In order to make the most accurate nosetip length measurements as the nosetip material heats up upon reentry, the ultrasonic wave velocity must also be known as a function of temperature. The temperature dependence of the ultrasonic longitudinal wave velocity in $\mathrm{C} / \mathrm{C}$ Pitch parent material and in Pitch/M2 core material is presented here from $70^{\circ} \mathrm{F}$ to $5400^{\circ} \mathrm{F}$.

The ultrasonic velocity versus temperature measurements were made with three separate 0.75 inch diameter rods which were machined from the full length Billet \#8, PN 9139. One 
rod, designated as ROD \#2, contained the Pitch/M2 core material of 0.675 inch diameter along the center axis of the rod. The other two rods, designated as ROD \#I and ROD \#3, consisted solely of the $\mathrm{C} / \mathrm{C}$ Pitch parent material.

During the performance of these tests, it was determined that ROD \# $I$ and ROD \#3 were not uniform in material properties, and there were differences in the ultrasonic velocity from end to end as well as from side to side in both rods. These differences were extensively investigated in order to explain the temperature dependence variations between the two rods. The variations are shown to be due to the material property differences of the two rods and not due to errors in the measurement technique of the velocities. It is known that one of the rods was taken from the corner of the billet and the other rod was taken from near the side of the billet. The specific identity of each rod is otherwise lost.

Comparative ultrasonic velocity measurements taken at different locations along the length of the same rod changed by as much as 15\%. Both rods exhibited these changes from end to end, but only ROD \#3 varied significantly from side to side, i.e., along the diameter of the rod. These measurements showed that a significant edge effect of material properties existed in the original billet. However, the velocity values of ROD \#I were uniform throughout the indexed section of the rod which was used for the temperature measurements. Therefore, the temperature data of ROD \#l are representative of the Pitch parent material, but the temperature data of ROD \#3 were influenced by the variation of the Pitch material properties in the transverse direction of that rod. 
Experimental Methods

The ultrasonic velocity measurements versus temperature were made in the same way as described previously ${ }^{1,2}$. The method uses the pulse echo technique, where an ultrasonic transducer is coupled to one end of an indexed rod. The indexed end of the rod is placed in the hot zone of a furnace and the transducer end of the rod is threaded into a wateredcooled brass holder to prevent excessive heating of the transducer during the test.

The indexed section of the rod is made by milling a right-cornered slot or notch into the side of the rod until a sufficient echo amplitude of the milled notch is present in the pulse echo wave trace. An indexed length from the notch to the end of the rod of 2.0 inches was provided in ROD \#1 and ROD \#3, and an indexed length of 1.5 inch was provided in ROD \#2. The depth of the milled notch was kept at a minimum in order to reduce interference of the pulse echo reflection of the notch with that of the end of the rod.

The data from room temperature to $5400^{\circ} \mathrm{F}$ was obtained in two stages. First, the rod was placed into a nickel-chromium resistance wire element furnace where the temperature was recorded using a chromel-alumel thermocouple. The temperature was increased in approximately 125 degree increments between data points, from room temperature up to about $1100^{\circ} \mathrm{F}$. The rod was then cooled to room temperature and placed in the high temperature furnace where the temperature was recorded using an optical pyrometer. Data was taken at approximately 125 
degree increments from $1250^{\circ} \mathrm{F}$ to $1800^{\circ} \mathrm{F}$ and then in $400^{\circ} \mathrm{F}$ increments up to $5400^{\circ} \mathrm{F}$. The optical pyrometer reading was corrected to an observed temperature value by adding the calibration correction of the pyrometer (calibrated on $11 / 7 / 84$ ) plus the quartz window correction of the furnace to the pyrometer reading.

The ultrasonic velocity in the rod material is calculated at each temperature point by measuring the delay time difference between the correct pair of echo peaks from the notch and the end of the rod. The velocity is given by

$$
V=\frac{2 L}{t}
$$

where $t$ is the measured delay time and $L$ is the indexed length of the rod from the notch to the end of the rod. The length $L$ at temperature is calculated by correcting the indexed length $I_{0}$ for thermal expansion. Data on the thermal expansion was supplied by Lockheed for the $z$ direction of the rod for both the Pitch and the Pitch/M2 material. A least squares polynomial fit of the thermal expansion data from billet \#8060 was used for the calculations. For the Pitch material the following was used,

$$
\begin{aligned}
\left(\mathrm{L}-\mathrm{L}_{0}\right) / \mathrm{L}_{0}= & 0.0319724 \times 10^{-3}-0.0904352 \times 10^{-5} \mathrm{~T} \\
& +8.63546 \times 10^{-10} \mathrm{~T}^{2}-1.94355 \times 10^{-13} \mathrm{~T}^{3} \\
& +1.95864 \times 10^{-17} \mathrm{~T}^{4}
\end{aligned}
$$


and for the Pitch/M2 material the following was used

$$
\begin{aligned}
\left(L-L_{0}\right) / L_{0}= & -0.0770611 \times 10^{-3}+0.12929 \times 10^{-5} \mathrm{~T} \\
& -0.0250908 \times 10^{-8} \mathrm{~T}^{2}+1.95546 \times 10^{-12} \mathrm{~T}^{3} \\
& -5.29327 \times 10^{-16} \mathrm{~T}^{4}+4.84666 \times 10^{-20} \mathrm{~T}^{5}
\end{aligned}
$$

where $T$ is in degrees Fahrenheit.

The delay time measurement between the pair of echoes from the notch and the end of the rod was determined with the apparatus shown schematically in Figure 1. The ultrasonic waveform, including the pair of echoes of interest, was recorded independently by the boxcar integrator $/ x-y$ plotter system and by the Biomation/PDP $11 / 34$ computer system. The $x$ axis of the plotter in the boxcar integrator system was calibrated at one microsecond per centimeter, using the calibrated time mark generator as the reference source. The waveforms were digitized with the Biomation transient digitizer using a 0.05 microsecond sample interval.

An improved transducer pulsing technique (not used previously) was employed for these tests. The present pulsing technique allows excitation of the transducer with integral cycles of a pure sine wave at a set frequency. This allows efficient power input near the resonant frequency of the transducer, as well as a means of measuring the velocity in the dispersive material at a set frequency. For all the temperature dependent velocity measurements, the pulser was set to a frequency of 200 or $300 \mathrm{KHz}$ with a pulse length of one cycle. The transducer used in the temperature tests was a 
one-inch diameter, highly-damped, wide-band $500 \mathrm{KHz}$ transducer.

The ultrasonic waveform at each temperature point was recorded on the $x-y$ plotter and also digitized with the Biomation PDP $11 / 34$ computer system. After completion of the test, a delay time measurement and the relative shift in delay time from the room temperature value was calculated from each waveform using a pair of echo peaks, one from the notch echo and another from the rod end echo. The relative shift in the delay time from the room temperature value was then used to calculate the correct delay time $t$ at the given temperature which was used in Equation (1).

Preparation of the Test specimens and Recorded Temperature Data

The procedure for preparing the rod specimens and measuring the temperature dependence of the ultrasonic velocity was identical for all three rods. Preliminary longitudinal pulse echo velocity determinations were made on the rods before the notches were machined in the rods. The frequency of the applied pulse was varied, and round trip delay time measurements were made to determine the room temperature velocity of the rod material, as well as check for optimum echo waveforms which could be used to make the temperature tests. Optimum waveforms were obtained when the frequency was set between $150 \mathrm{KHz}$ to $300 \mathrm{KHz}$.

When the optimum waveform of the rod end reflection was obtained, an indexed length for machining the notch was 
decided upon from the room temperature velocity value and the wave packet length of the rod end echo. The indexed length must be long enough so that excessive interference between the notch echo and the end echo is avoided, but it must be short enough so that the indexed length is well within the hot zone of the furnace. For the Pitch material and the Pitch/M2 material, indexed lengths of 2.0 and 1.5 inches respectively, met these requirements.

The rod with the transducer still attached was then mounted into the vice of a small milling machine. A notch was machined at the indexed length just deep enough so that the notch echo appearing in the waveform was distinct and of sufficient amplitude to be tracked during the temperature tests. After the milling process, the notched rod was placed into the furnace and the temperature tests were conducted.

The $x-y$ plots of the initial pulse echo waveforms of the rod end reflections versus frequency, the sequential waveforms of the milling process, and the waveforms of the low and high temperature tests are all shown in Appendices $A, B$ and $C$ for ROD \#1, ROD \#2 and ROD \#3 respectively.

Plots of the digitized waveforms, along with the measured relative shift of the notch echo and the rod end echo from the room temperature delay time value, are shown in Figures 2 through 6 for the three rods. The high-temperature, digitized data for ROD \#I is not included in these figures because an unexpected electrical interference problem existed between the Biomation digitizer and the high-temperature furnace controller. This problem was solved in subsequent high 
temperature tests by momentarily turning off the furnace while the waveform was being digitized.

\section{Temperature Test Results}

The temperature data of the ultrasonic velocity as determined from the waveforms of the Appendices and Figures 2 through 6 are shown in Tables I, II, and III for the three rods. The normalized velocity value at each temperature is also given in the Tables where the room temperature velocity value for each rod was taken as the normalizing velocity. Table I contains data obtained with ROD \#1 for a low temperature test at $200 \mathrm{KHz}$, a high-temperature test at 200 $\mathrm{KHz}$, and second low-temperature test at $300 \mathrm{KHz}$. The second low-temperature test was conducted to check the system for errors, as well as confirm that the temperature dependence of the data of ROD \#l was slightly different from that of ROD \#3.

Plots of the normalized velocity versus temperature for all the data in the Tables are shown in Figures 7,8 , and 9 for the three rods. As seen from Figures 7 and 9, a difference in the temperature dependence of ROD \#I and ROD \#3 is observed, even though the rods are of the same parent material. Inconsistant room temperature values of ROD \#3 between the pulse echo end reflection velocity $(8.89$ $\mathrm{mm} / \mathrm{microsecond),} \mathrm{with} \mathrm{the} \mathrm{indexed} \mathrm{length} \mathrm{velocity} \mathrm{value} \mathrm{(9.83}$ $\mathrm{mm} / \mathrm{microsecond),} \mathrm{indicated} \mathrm{that} \mathrm{this} \mathrm{rod} \mathrm{was} \mathrm{not} \mathrm{uniform} \mathrm{in}$ properties from end to end. In order to show that ROD \#3 was anomalous and that the data of ROD \#l was representative of the Pitch parent material, an extensive study of the velocity variations in these two rods was undertaken. 
Material Property Variations of ROD \#I and ROD \#3

After all temperature tests were completed, ROD \#I and ROD \#3 were machined with flat surfaces perpendicular to the $\mathrm{X}$-direction of the $\mathrm{C} / \mathrm{C}$ composite along the full length of the rods. This provided a constant thickness in the $\mathrm{x}$-direction of the rod, through which ultrasonic through-transmission velocities could be determined at positions along the length of the rod.

Through-transmission delay time measurements were accomplished at locations along the rods using a pair of 500 $\mathrm{KHz}$ 0.25-inch diameter transducers and the Biomation/PDP $11 / 34$ system. The waveforms of the lst half cycle of the throughtransmission pulse were recorded at 0.01 microsecond per sample interval, and the delay time of the peak was used for the velocity calculations. The waveforms recorded in the $\mathrm{x}-$ direction of the two rods, with an applied single cycle 300 $\mathrm{KHz}$ pulse as the transducers were moved along the length of the rod, are shown in Figures 10 and 11 . The delay time measurement at each position is also listed in the Figures. The ultrasonic velocity calculated at each position along the rod is plotted in Figure 12 for both ROD \#1 and ROD \#3.

From Figure 12, the velocity in the $\mathrm{x}$-direction is seen to decrease by $15 \%$ near each end of the rod. ROD \#3 shows a larger change for the velocity in the indexed end of the rod than ROD \#I. But this difference does not explain the apparent faster velocity in the $\mathrm{z}$-direction for the indexed region of ROD \#3 as measured in Appendix $C$. 
To investigate the material property differences further, the rods were also machined with flat surfaces perpendicular to the Y-direction of the composite. The through-transmission velocity values obtained in the indexed region of each rod using a $500 \mathrm{KHz}$ applied pulse are shown in Figure 13. A 500 $\mathrm{KHz}$ applied pulse was used because it provided slightly more resolution of the peak than the $300 \mathrm{KHz}$ pulse. A slightly higher velocity value was obtained at $500 \mathrm{KHz}$ than at $300 \mathrm{KHz}$ at the same location indicating the dispersion characteristics of the composite. In Figure 13, the velocities in the $\mathrm{Y}-$ direction on the notched side of ROD \#3 are about 10\% lower than they are in the other portions of the rod. ROD \#l is fairly uniform in this respect.

The lower velocities of ROD \#3, as shown in Figure 13, imply that the velocity in the z-direction may also be low at the notched side of the rod. To confirm this supposition, ROD \#1 and ROD \#3 were cut into three pieces with parallel faces machined perpendicular to the $\mathrm{z}$-direction of the rod. One piece contained the indexed top region of the rod and was about 1.7 inches long. The second piece of about 1.7 inch length was taken from the middle of the rod just below the notch of each rod. The third piece consisted of the bottom half of each rod, which was approximately 5.3 inches long. Accurate through-transmission velocity measurements at $500 \mathrm{KHZ}$ applied pulse were taken along the $\mathrm{z}$-direction of each piece at various axial locations. The results of these measurements are also shown in Figure 13.

From Figure 13, it is clearly shown that the material on the notch side of ROD \#3 has a significantly lower velocity than the other portion of the rod. In comparison, the 
velocities measured on $R O D \# 1$ are rather uniform from one side of the rod to the other. The slower velocity value measured on the notch side of ROD \#3 is in agreement with the apparent fast velocity value of the indexed length as measured in Appendix $C$. As seen in Appendix $C$ during the milling of the notch of ROD \#3, the rod end reflection echo shifted by -1.3 microseconds. No shift of the end reflection echo is expected if the material in the rod is uniform from one side of the rod to the other side.

The -1.3 microsecond shift is explained by noting that the end reflection echo is a mixture of fast and slow velocity echoes with the slow velocity echo predominating. Then, by milling the notch, a large portion of the slow velocity end echo is being blocked and the fast velocity end echo becomes dominant. The notch echo is still from the slow velocity material, but the end echo is that of the fast velocity material; therefore, the calculation of the velocity in the indexed region of ROD \#3 is not correct by using the delay time measurement between the notch echo and the end echo.

There is also evidence of a mixture of two echoes present in the end echo of ROD \#3, which was observed during the hightemperature test illustrated in Figure 6 . In this test from about $900^{\circ} \mathrm{C}$ to $3000^{\circ} \mathrm{C}$, a confusion of double echo peaks appeared in the end reflection echo as if one set of echo peaks was moving from right to left through a second stationary set of echo peaks as a function of temperature. Waveforms were also taken in this test on decreasing temperature, which are displayed in Appendix $c$, where they show that the separation and merging of the double peaks was reversible. Although the delay time data for ROD \#3 was 
processed by tracking the notch echo peaks with the second rather stationary end echo peaks as well as possible, and the results are presented in this report, it is concluded that judging from the nonuniformity of material properties of ROD \#3 from side to side, it is not representative of the interior Pitch parent material of a normal shape stable billet.

\section{Measurement Errors}

The delay time measurements at each temperature were made to ${ }_{-}^{+} 0.1$ microsecond. This represents an error of approximately $1 \%$ for the velocity of the Pitch parent material and about a $0.5 \%$ for the velocity of the Pitch/M2 material. The temperature readings are estimated to be within $1 \%$ or better. A room temperature delay time measurement was taken before and after each temperature test, and the maximum shift recorded was 0.15 microseconds for the second low temperature test of ROD \#1. Therefore, the maximum systematic error due to drift of the electronic equipment was no greater than $1.3 \%$.

\section{Summary and Conclusions}

The longitudinal velocity was determined for Pitch parent material and Pitch/M2 material from $70^{\circ} \mathrm{F}$ to $5500^{\circ} \mathrm{F}$. The velocity in the Pitch parent material was constant from room temperature to $5000^{\circ} \mathrm{F}$, where a slight increase in velocity occurred. The velocity in the Pitch/M2 material was constant from room temperature to $1500^{\circ} \mathrm{F}$, where it increased to a maximum at $4000^{\circ} \mathrm{F}$, and then decreased rapidly for higher 
temperatures. The maximum temperature for which the velocity in the Pitch/M2 material could be measured was about $4900^{\circ} \mathrm{F}$, where the M2 material changed phase which prevented any additional measurements to be made.

Two rods of the Pitch parent material from the same billet displayed slightly different temperature dependence of the velocity. A thorough investigation of the velocity in the major axes of the rods, showed that the billet from which the rods were machined contained material property differences at the edges of the billet, which resulted in a $15 \%$ decrease in the ultrasonic velocity. The temperature dependence of the velocity for one of these rods was influenced by this material property difference. 


\section{References}

1. J. H. Gieske, "Ultrasonic Shear and Longitudinal Wave Velocities in CMT Graphite and Carbon-Carbon (226)

From $70^{\circ} \mathrm{F}$ to $5400^{\circ} \mathrm{F}$," SAND76-0434, Sandia Laboratories, Albuquerque, New Mexico, April 1977.

2. J. H. Gieske, "Ultrasonic shear Wave Velocity in CLF/CMT Graphite from Room Temperature to $2000^{\circ} \mathrm{F}$," SAND80-1850, Sandia National Laboratories, Albuquerque, New Mexico, November 1980 . 


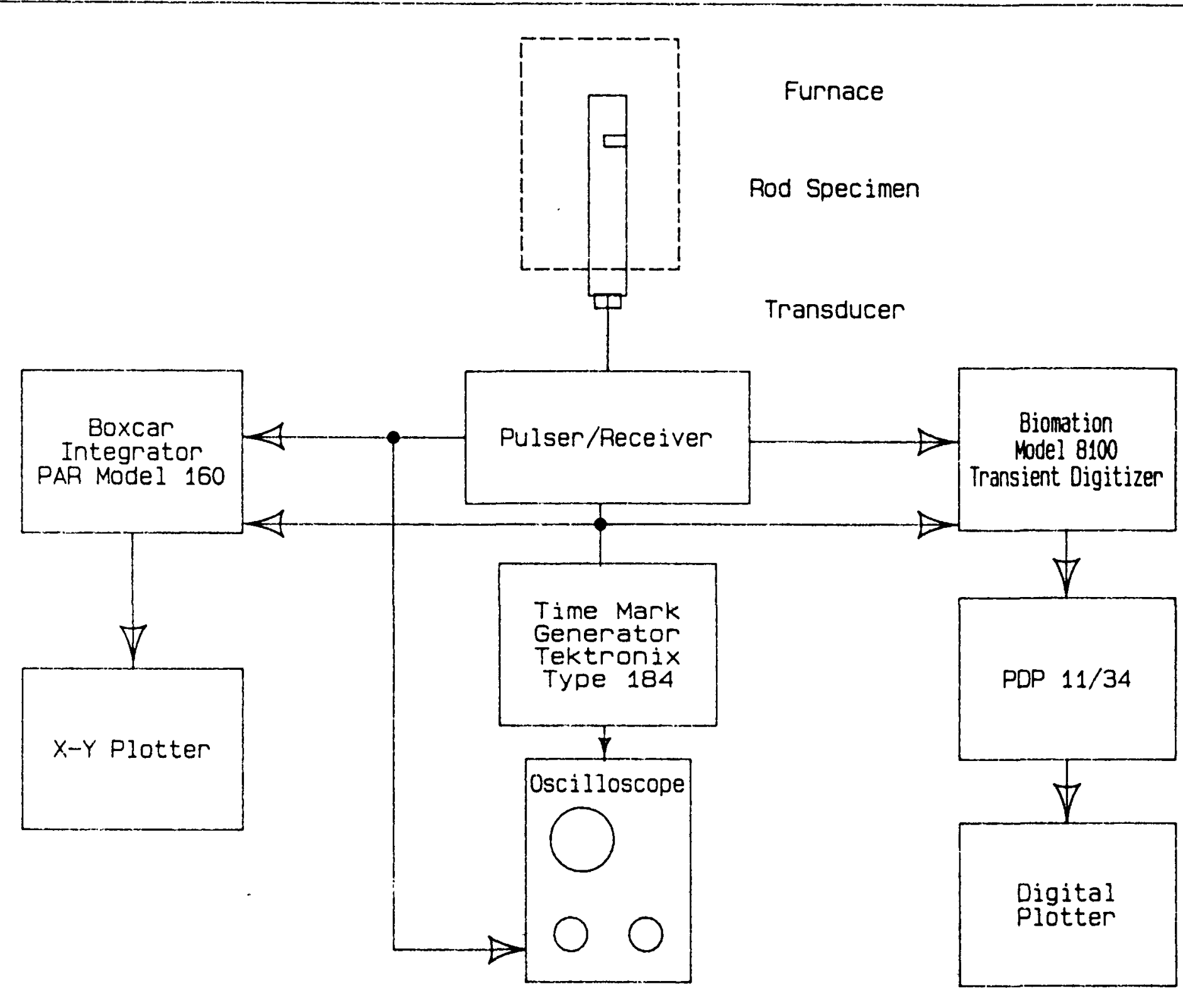

Figure 1. Schematic Diagram of Electronics to Record Pulse Echo Waveforms with the Analog System and the Digital System. 
$\begin{array}{llll}0 & 5 & 10 & 15\end{array}$

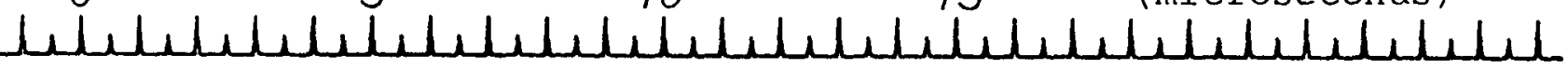

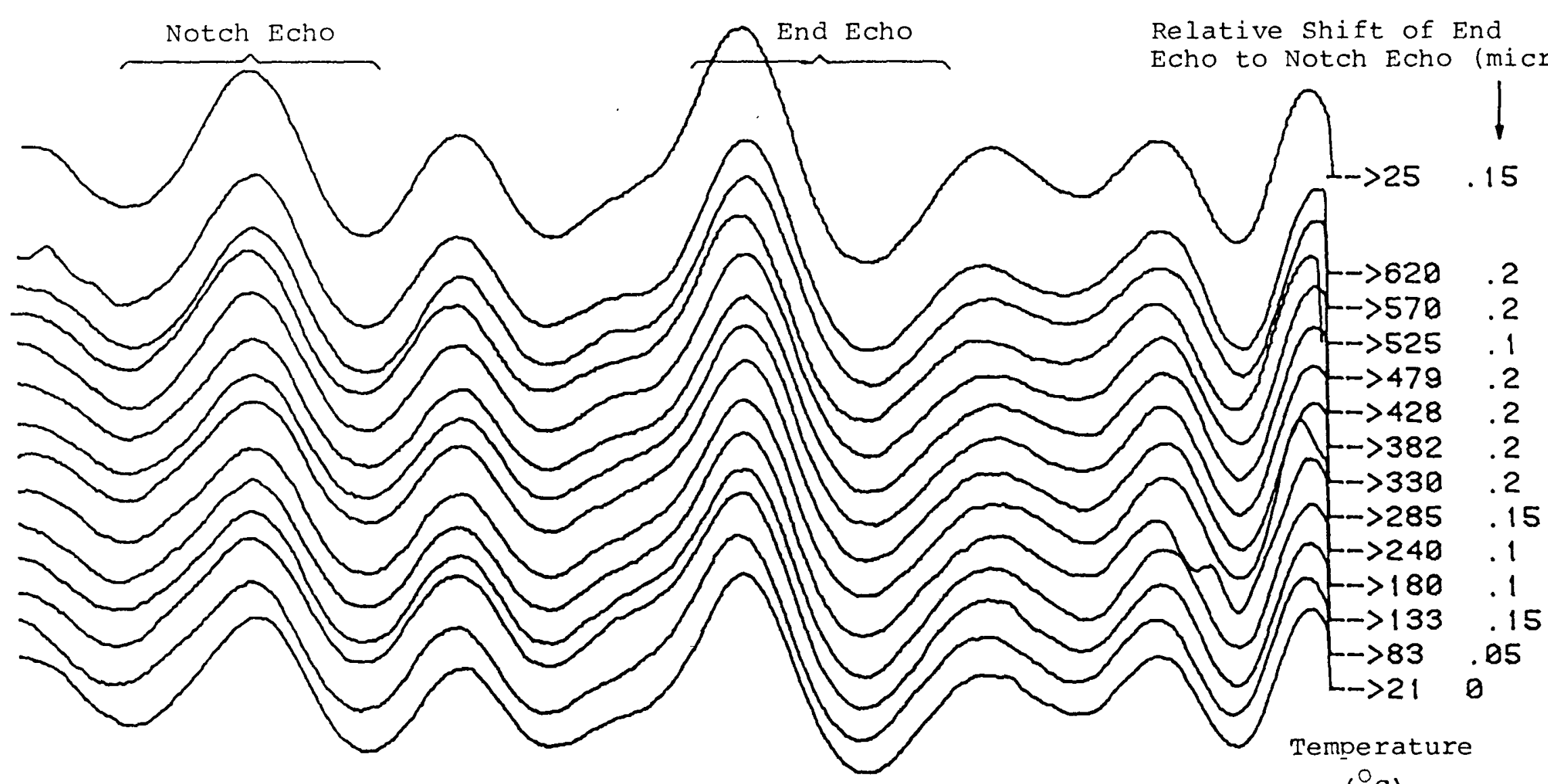

${ }_{0}$ $\left({ }^{\circ} \mathrm{C}\right)$

FIGURE 2 - DIGITIZED WAVEFORMS OF NOTCH ECHO AND END ECHO VERSUS TEMPERATURE FOR THE LOW TEMPERATURE TEST \#2 OF ROD \# 1 


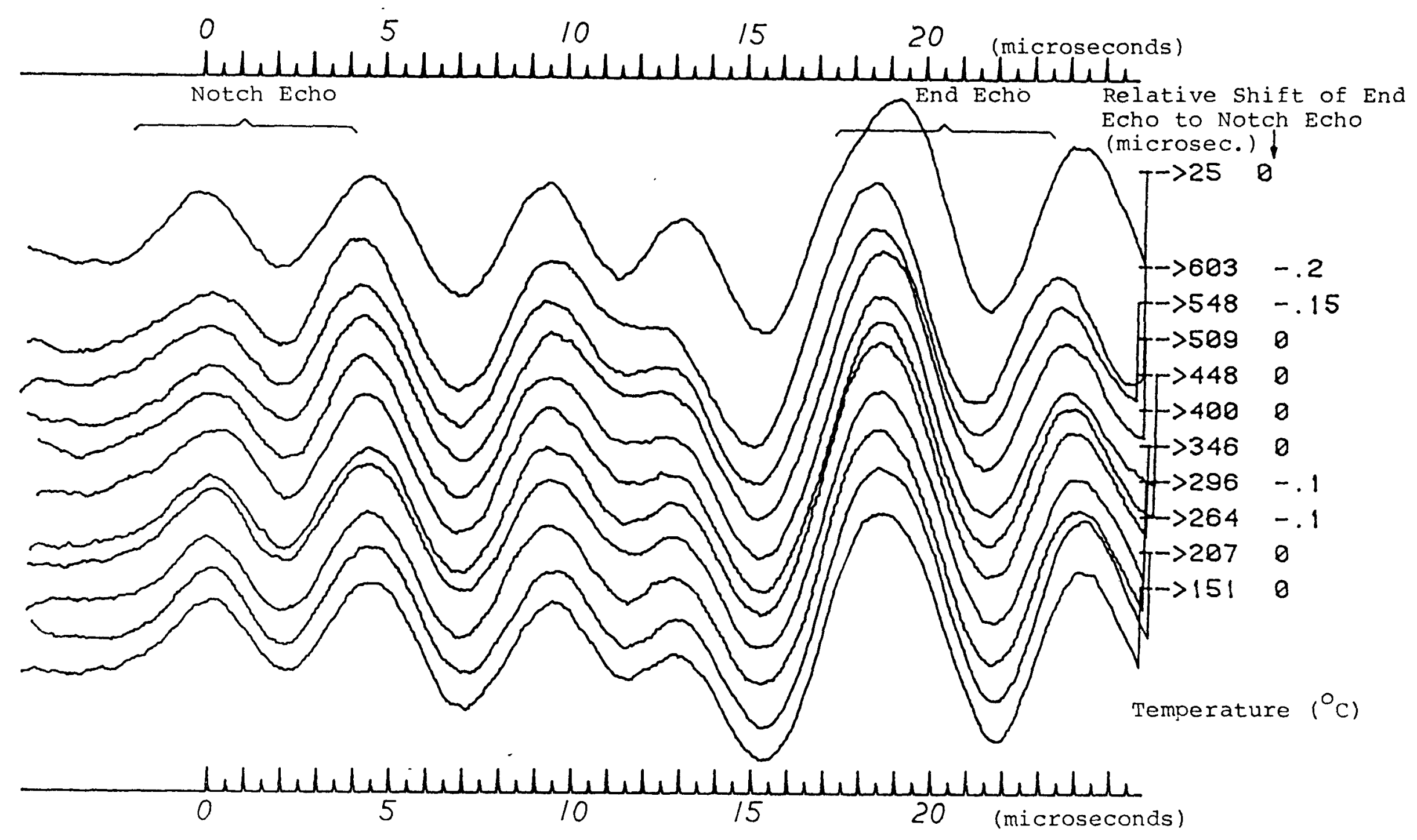

FIGURE 3 - DIGITIZED WAVEFORMS OF NOTCH ECHO AND END ECHO VERSUS TEMPERATURE FOR THE LOW TEMPERATURE TEST OF ROD \#2 
$\begin{array}{lllll}0 & 5 & 10 & 15 & \text { (microseconds) }\end{array}$

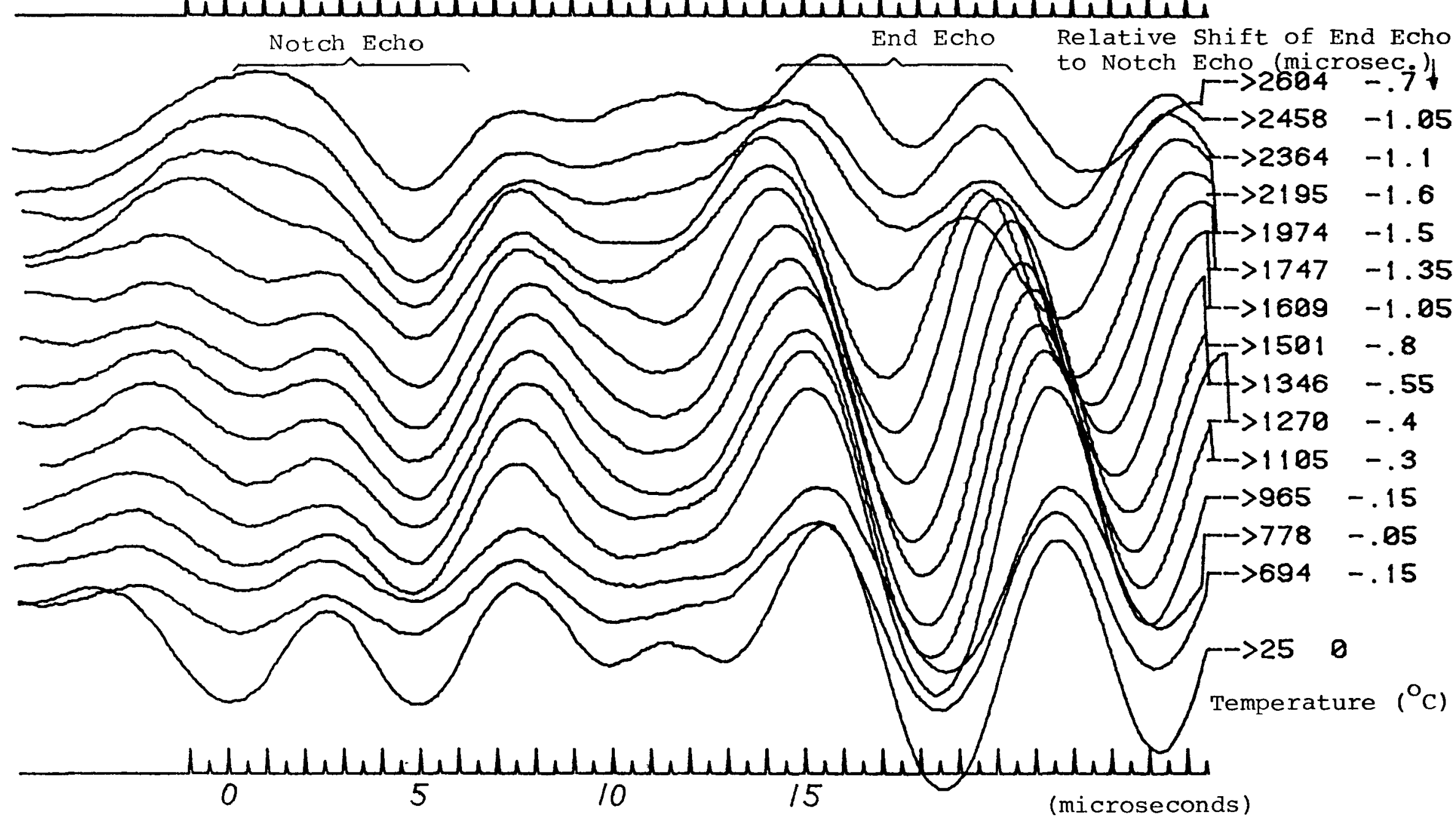

FIGURE 4 - DIGITIZED WAVEFORMS OF NOTCH ECHO AND END ECHO VERSUS TEMPERATURE FOR THE HIGH TEMPERATITE TEST OF ROD \#2 


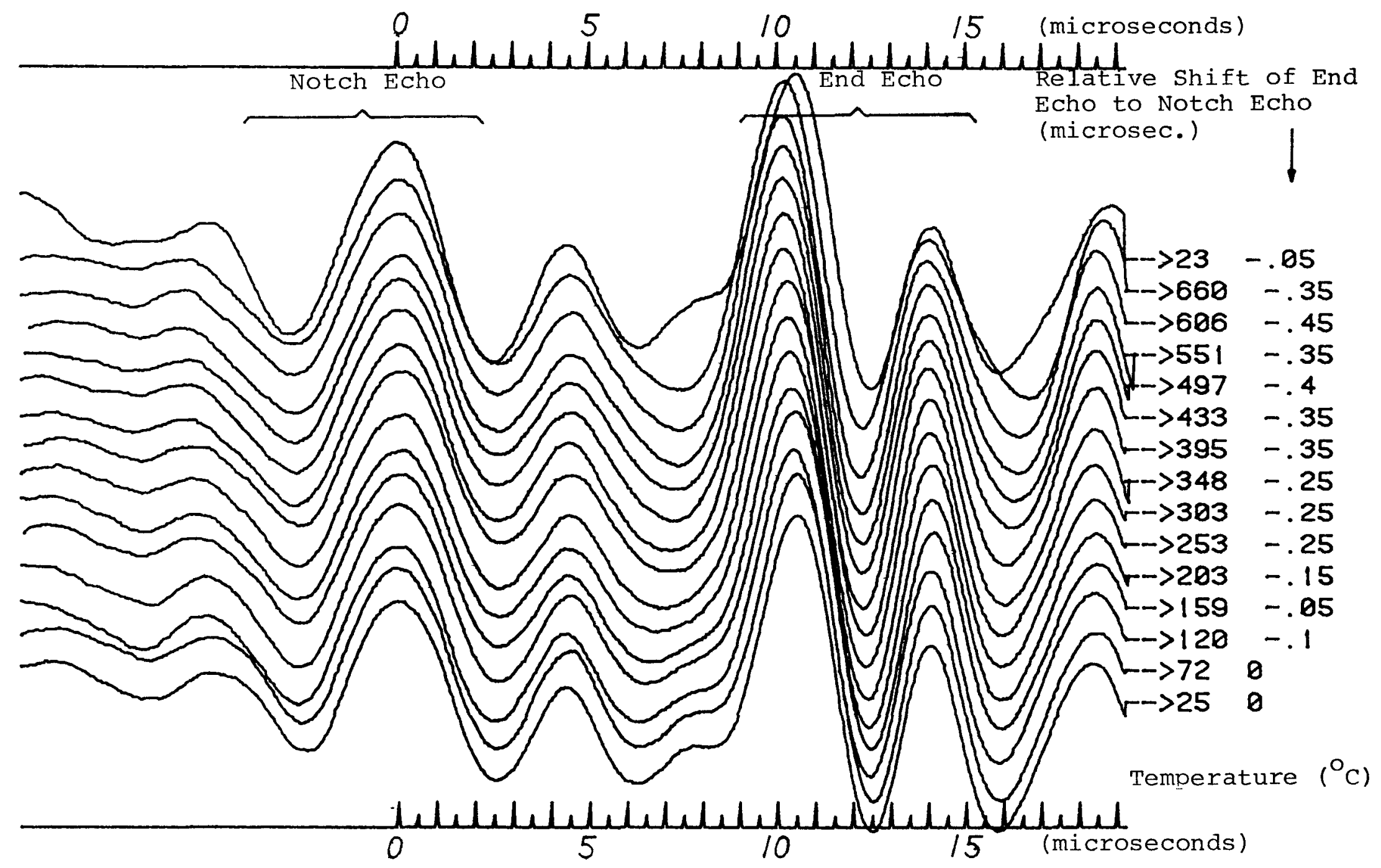

FIGURE 5 - DIGITIZED WAVEFORMS OF NOTCH ECHO AND END ECHO VERSUS 


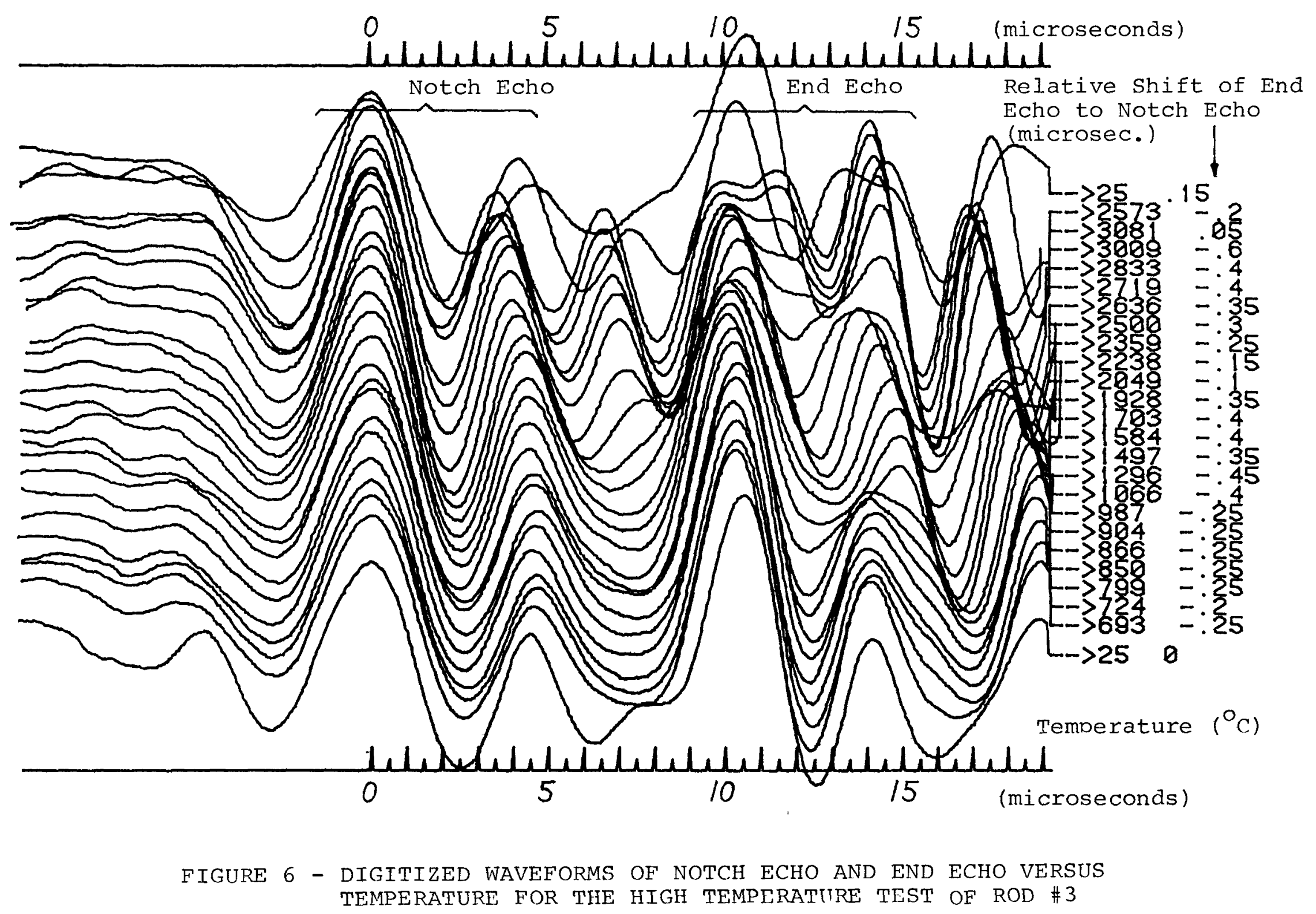




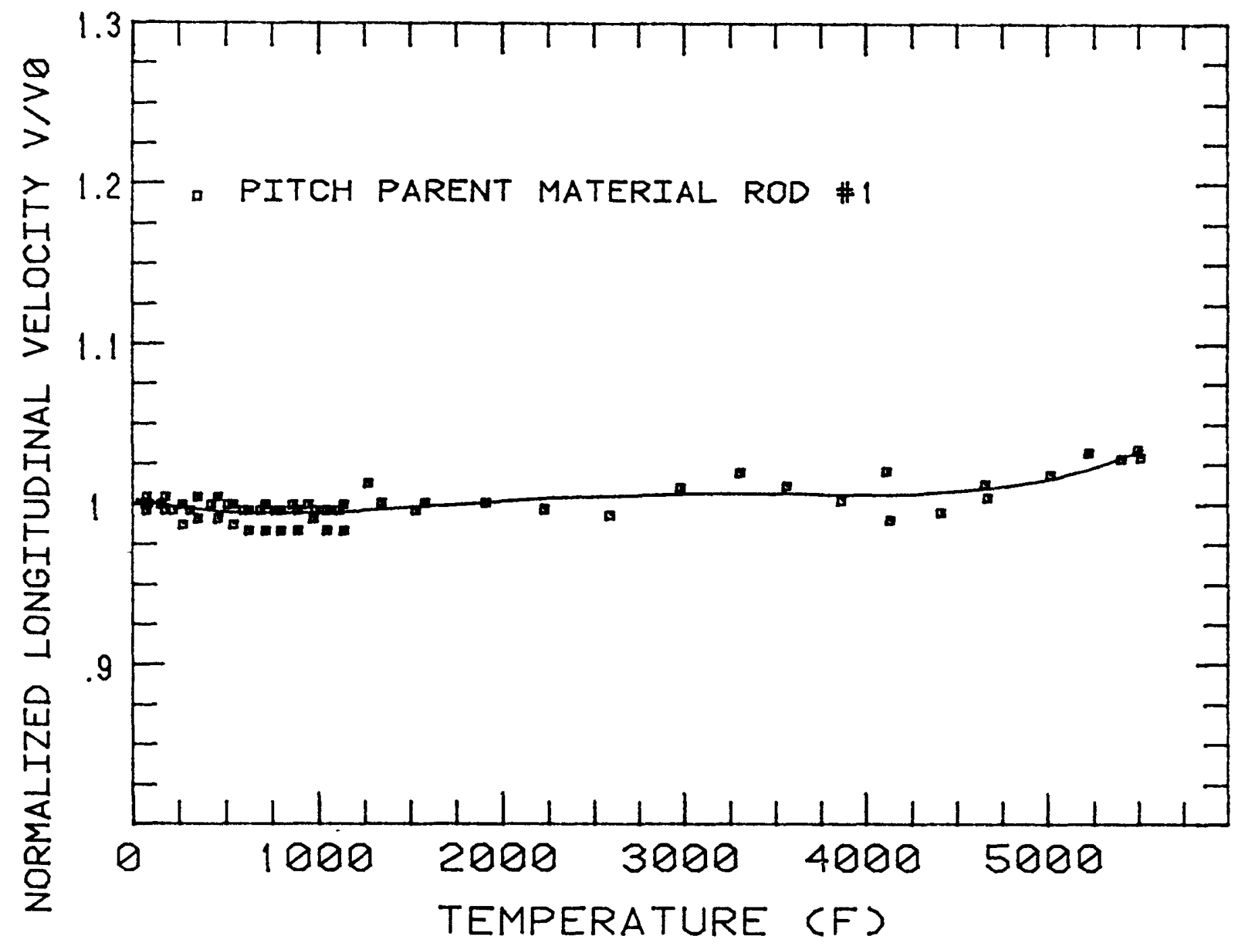

FIGURE 7 - NORMALIZED IONGITUDINAL VELOCITY VERSUS TEMPERATURE FOR ROD \#I, VO $=8.796 \mathrm{~mm} /$ MICROSECOND 


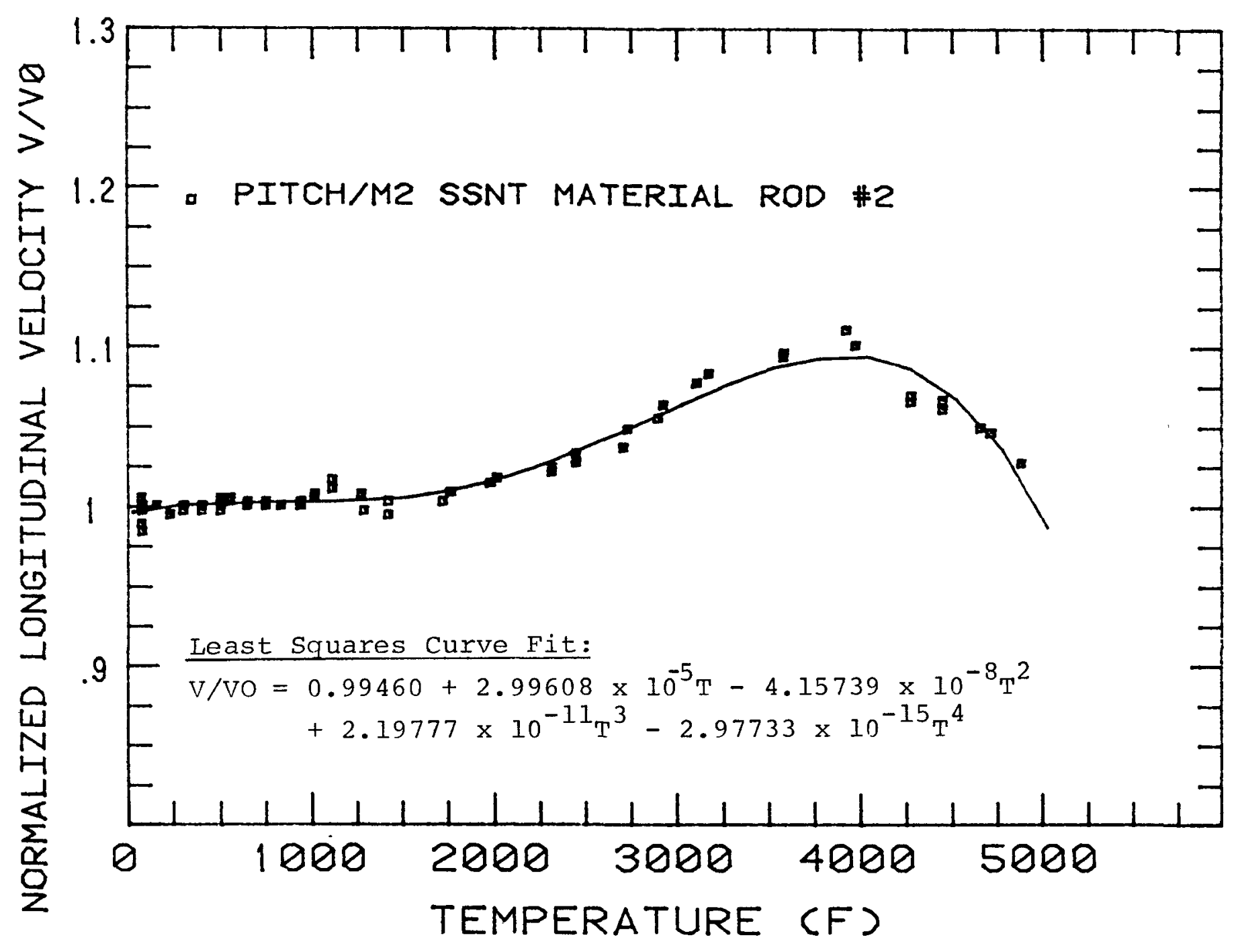

FIGURE 8 - NORMALIZED LONGITUDINAL VELOCITY VERSUS TEMPERATURE FOR ROD \#2, VO $=4.187 \mathrm{~mm} /$ MICROSECOND 


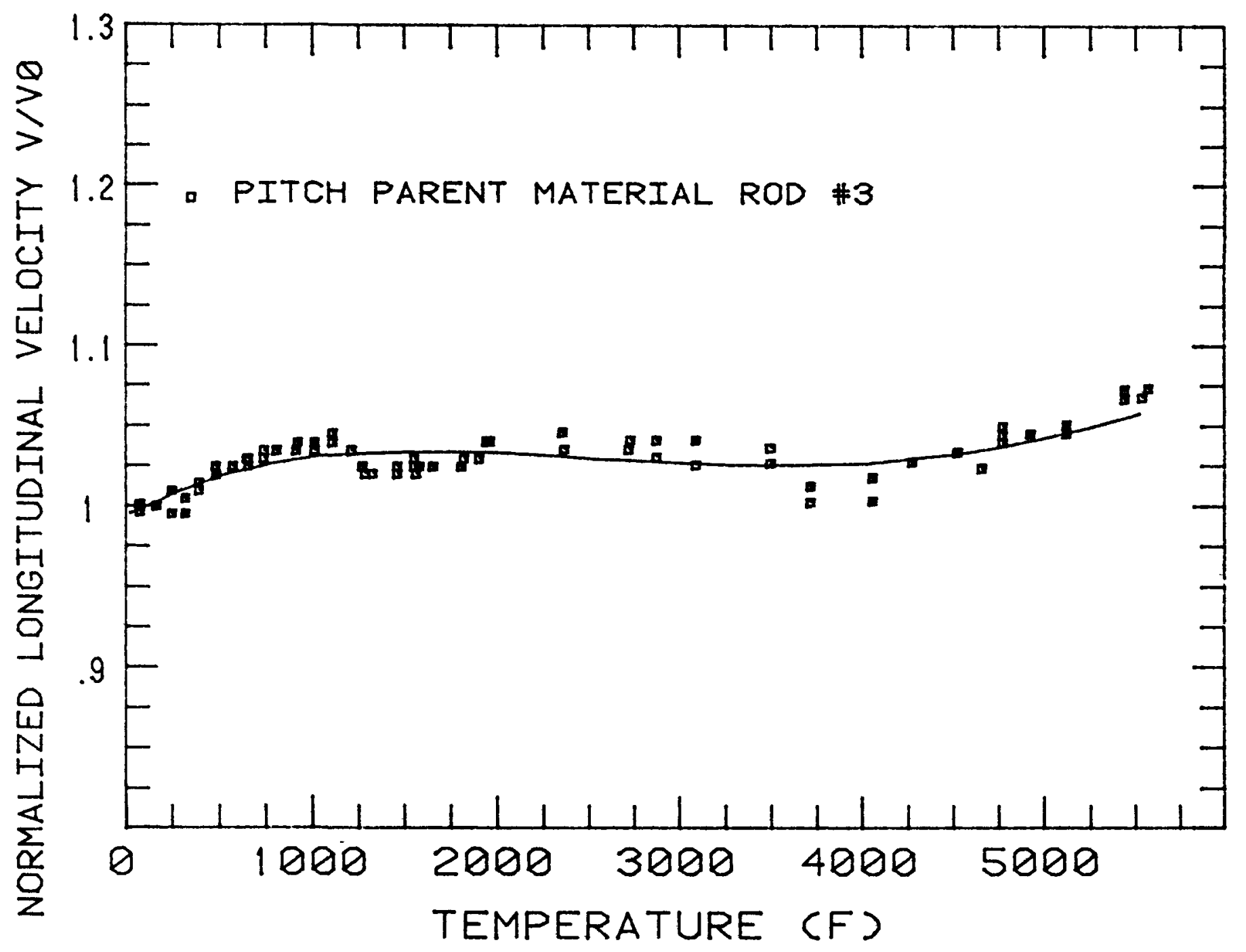




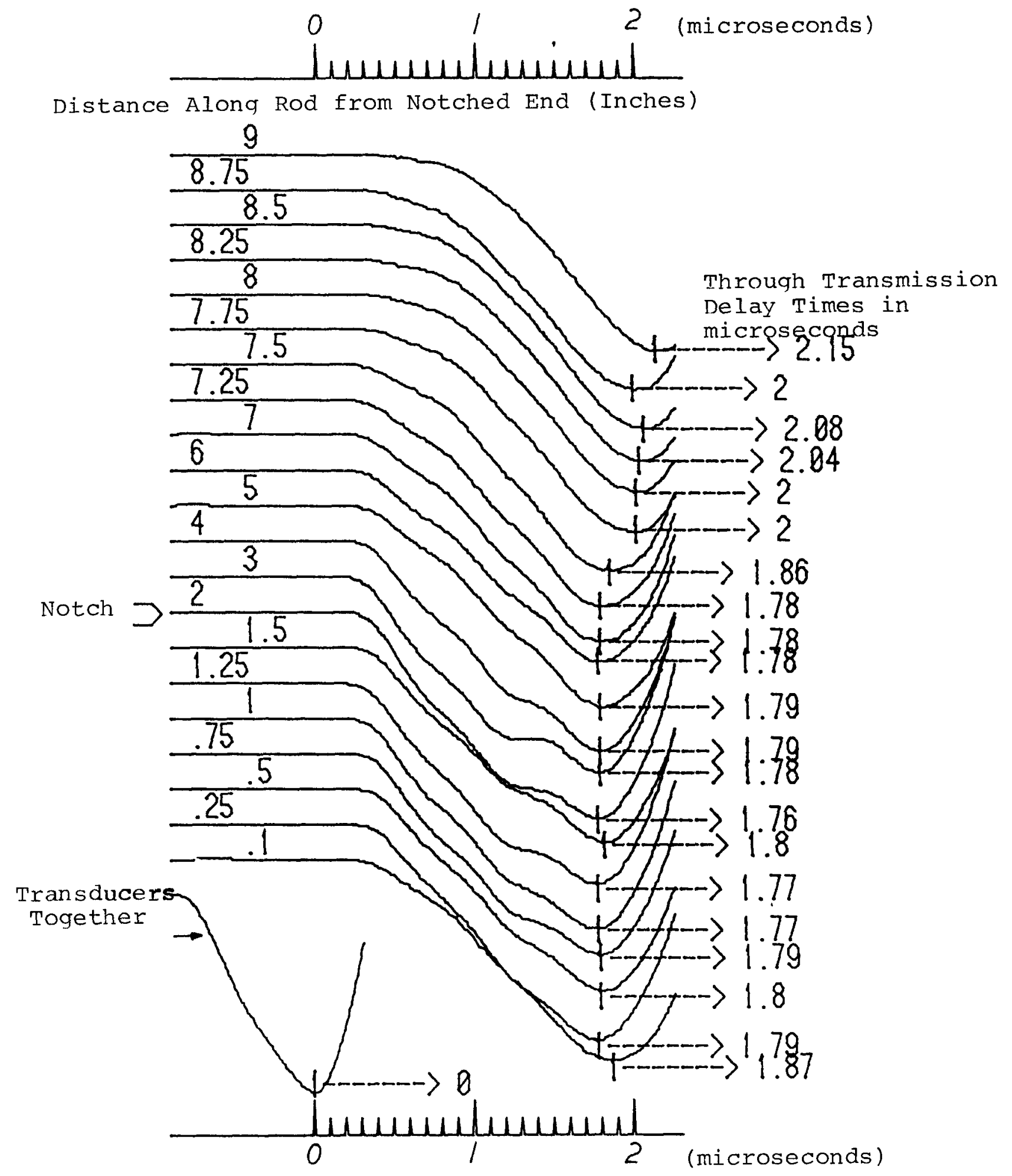

FIGURE 10 - THROUGH TRANSMISSION WAVEFORMS AND DEIAAY TIMES IN THE X-DIRECTION OF ROD \#I AT AXIAL LOCATIONS ALONG THE ROD. $X$ DIMENSION EQUALS 0.625 INCHES. 


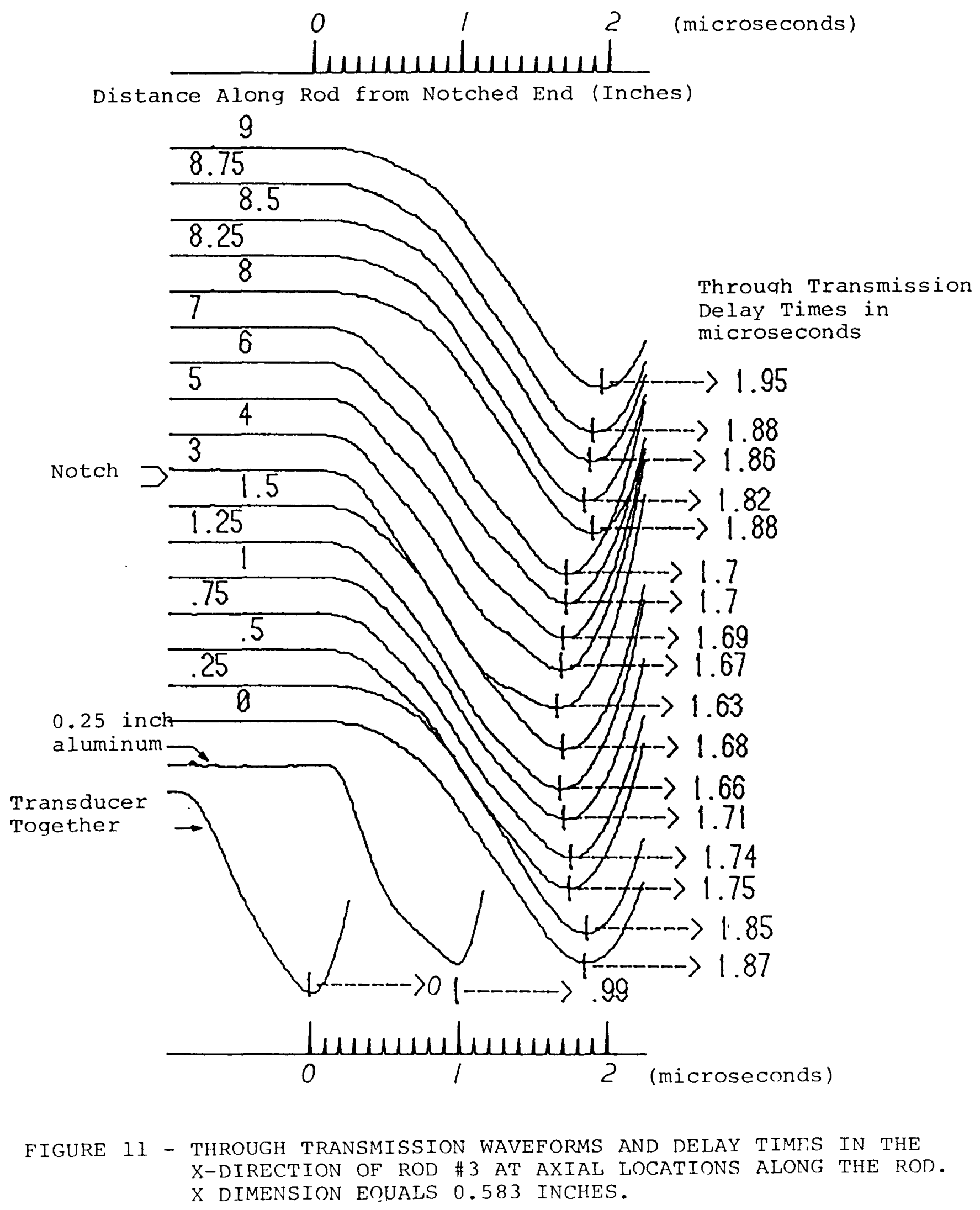




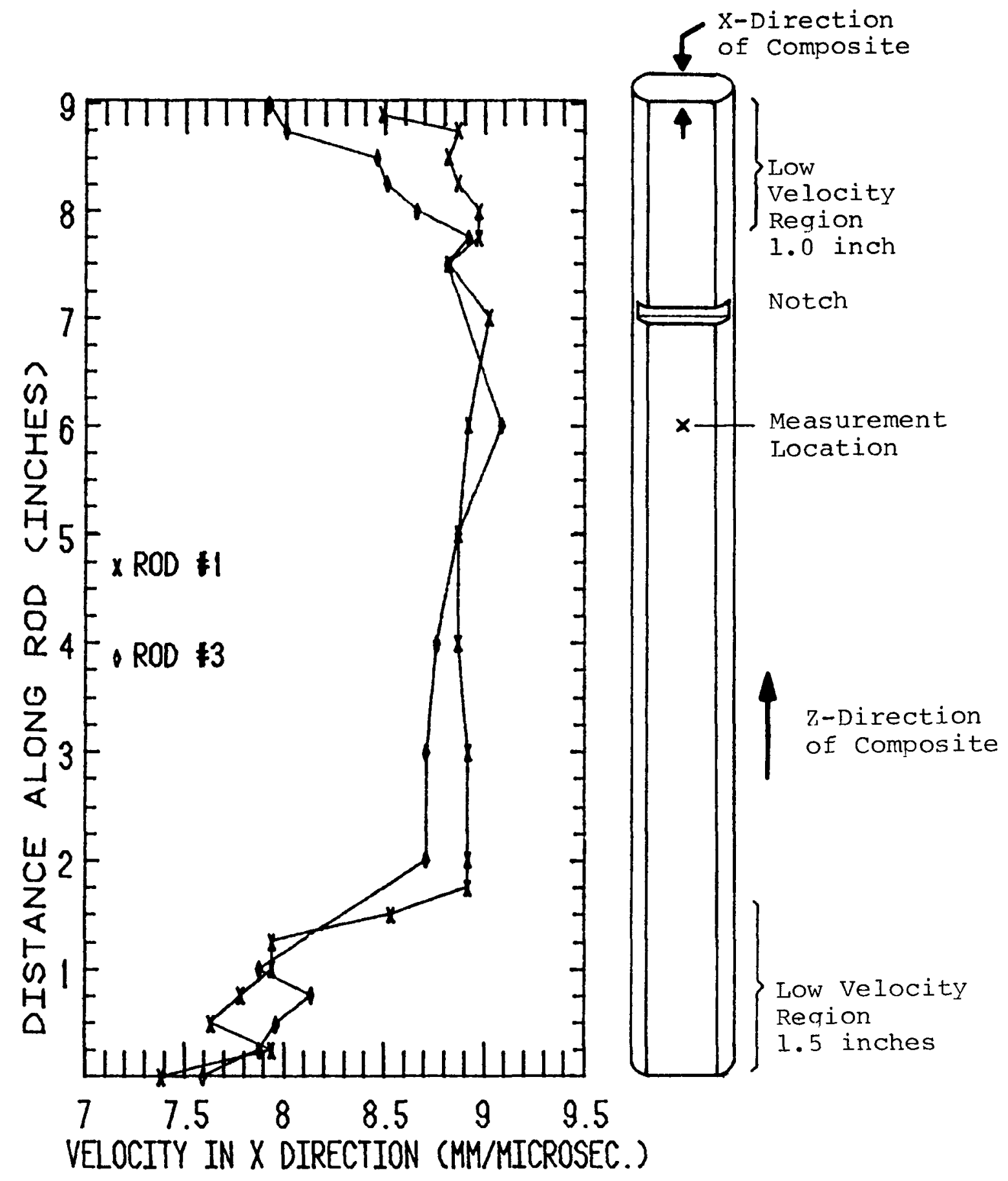

\footnotetext{
FIGURE 12 - VARIATION OF LONGITIDINAL VELOCITY IN THE $X$-DIRECTION OF THE COMPOSITE ALONG THE LENGTH OF ROD \#I and ROD \#3
} 


\section{ROD \#1}

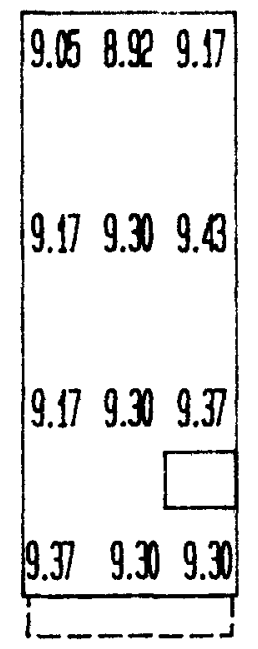

Notch

\section{Y-DIRECTION}

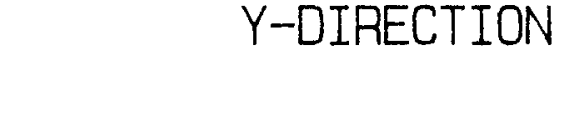

Velocity Values in $\mathrm{mm} / \mathrm{microsecond}$

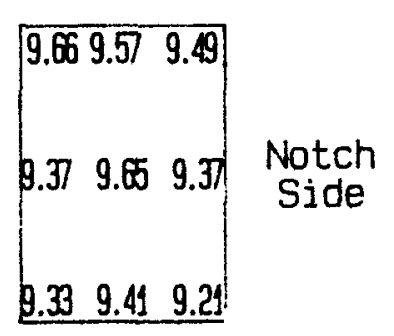

$$
\text { Z-DIRECTION }
$$

Top of Rod

0.339 .419 .24

\begin{tabular}{llll}
\hline 9.40 & 9.72 & 9.39 \\
3.72 & 9.81 & 9.72 \\
9.75 & 9.55 & 9.59 \\
\hline
\end{tabular}

Middle of Rod

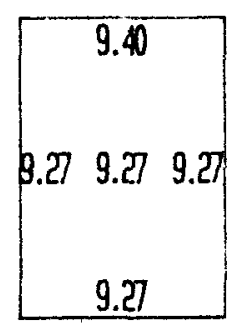

\section{ROD \#3}

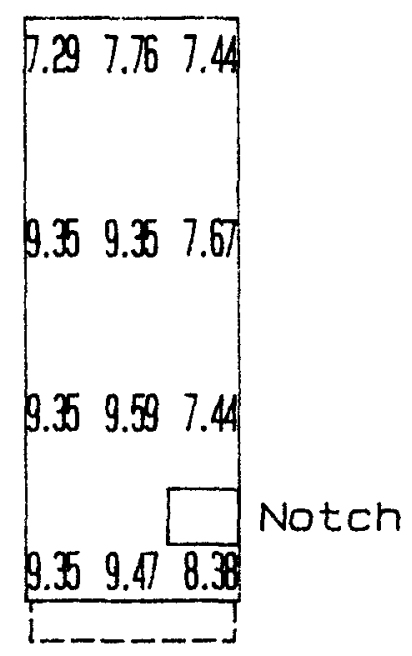

$\begin{array}{llll}9.39 & 9.71 & 9.04 \\ 9.39 & 10.0 & 9.23 & \begin{array}{l}\text { Notch } \\ \text { Side }\end{array} \\ 9.27 & 9.47 & 9.00 & \end{array}$

$\begin{array}{cccc}9.45 & 9.80 & 8.97 \\ 9.58 & 10.1 & 9.22 \\ 9.45 & 9.67 & 9.16\end{array}$

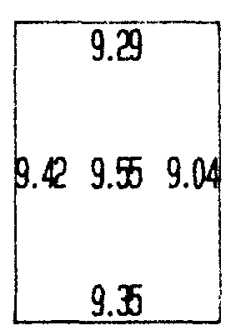

Figure 13. Longitudinal Velocity Determinations at Various Locations in the Y-Direction and Z-Direction for ROD \#1 and ROD\#3. 
TABLE I

Longitudinal Velocity Temperature Data for ROD \#I Pitch Parent Material

\begin{tabular}{|c|c|c|c|c|}
\hline $\begin{array}{l}\text { Corrected } \\
\text { Temperature }\end{array}$ & $\begin{array}{l}\text { Corrected } \\
\text { Index length, }\end{array}$ & $\begin{array}{l}\text { Measured } \\
\text { Delay Time, }\end{array}$ & $\begin{array}{l}\text { Calculated } \\
\text { Velocity, }\end{array}$ & $\begin{array}{l}\text { Normalizec } \\
\text { Velocity, }\end{array}$ \\
\hline$\left({ }^{\circ} \mathrm{C}\right) \quad\left({ }^{\circ} \mathrm{F}\right)$ & $2 \mathrm{~L}(\mathrm{~mm})$ & $t(\psi(\sec )$ & $\mathrm{V}(\mathrm{mm} / / \mathrm{sec})$ & $\mathrm{V} / \mathrm{V}$ \\
\hline
\end{tabular}

LOW TEMPERATURE TEST \# 1

$\begin{array}{rrrr}22 & 71 & 101.597 & 11.55 \\ 67 & 152 & 101.591 & 11.55 \\ 103 & 217 & 101.587 & 11.60 \\ 155 & 311 & 101.583 & 11.60 \\ 219 & 426 & 101.579 & 11.55 \\ 270 & 518 & 101.577 & 11.55 \\ 318 & 604 & 101.576 & 11.60 \\ 369 & 696 & 101.576 & 11.60 \\ 410 & 770 & 101.576 & 11.60 \\ 464 & 867 & 101.578 & 11.55 \\ 510 & 950 & 101.580 & 11.55 \\ 536 & 996 & 101.581 & 11.60 \\ 580 & 1076 & 101.584 & 11.60 \\ 605 & 1121 & 101.586 & 11.60 \\ 26 & 78 & 101.597 & 11.60\end{array}$

HIGH TEMPERATURE TEST

$\begin{array}{rccc}21 & 69 & 101.597 & 11.55 \\ 693 & 1279 & 101.593 & 11.40 \\ 736 & 1356 & 101.598 & 11.55 \\ 835 & 1535 & 101.609 & 11.60 \\ 864 & 1587 & 101.612 & 11.55 \\ 1049 & 1920 & 101.638 & 11.55 \\ 1224 & 2235 & 101.665 & 11.60 \\ 1424 & 2595 & 101.701 & 11.65 \\ 1641 & 2985 & 101.744 & 11.45 \\ 1822 & 3311 & 101.783 & 11.35 \\ 1964 & 3567 & 101.818 & 11.45 \\ 2134 & 3873 & 101.864 & 11.55 \\ 2270 & 4118 & 101.906 & 11.35 \\ 2280 & 4136 & 101.909 & 11.70 \\ 2437 & 4418 & 101.965 & 11.65 \\ 2573 & 4663 & 102.021 & 11.45 \\ 2584 & 4683 & 102.026 & 11.55 \\ 2771 & 5019 & 102.119 & 11.40 \\ 2885 & 5225 & 102.185 & 11.25 \\ 2989 & 5412 & 102.253 & 11.30 \\ 3041 & 5505 & 102.290 & 11.25\end{array}$

$\begin{array}{ll}8.796 & 1.000 \\ 8.796 & 1.000 \\ 8.758 & 0.996 \\ 8.757 & 0.996 \\ 8.795 & 1.000 \\ 8.795 & 1.000 \\ 8.757 & 0.995 \\ 8.757 & 0.995 \\ 8.757 & 0.995 \\ 8.795 & 1.000 \\ 8.795 & 1.000 \\ 8.757 & 0.996 \\ 8.757 & 0.996 \\ 8.757 & 0.996 \\ 8.758 & 0.996\end{array}$

$\begin{array}{ll}8.796 & 1.000 \\ 8.912 & 1.013 \\ 8.796 & 1.000 \\ 8.759 & 0.996 \\ 8.798 & 1.000 \\ 8.800 & 1.000 \\ 8.764 & 0.996 \\ 8.730 & 0.992 \\ 8.886 & 1.01 \\ 8.968 & 1.019 \\ 8.892 & 1.011 \\ 8.819 & 1.003 \\ 8.979 & 1.021 \\ 8.710 & 0.990 \\ 8.752 & 0.995 \\ 8.910 & 1.013 \\ 8.833 & 1.004 \\ 8.958 & 1.018 \\ 9.083 & 1.033 \\ 9.049 & 1.029 \\ 9.092 & 1.034\end{array}$


TABLE I continued;

$\begin{array}{rrrrrr}3051 & 5523 & 102.297 & 11.30 & 9.053 & 1.029 \\ 26 & 78 & 101.597 & 11.50 & 8.834 & 1.004\end{array}$

LOW TEMPERATURE TEST \#2

$\begin{array}{rrrrrr}21 & 69 & 101.597 & 11.55 & 8.796 & 1.000 \\ 83 & 181 & 101.589 & 11.50 & 8.834 & 1.004 \\ 133 & 271 & 101.584 & 11.55 & 8.795 & 1.000 \\ 180 & 356 & 101.581 & 11.50 & 8.833 & 1.004 \\ 240 & 464 & 101.578 & 11.50 & 8.833 & 1.004 \\ 284 & 543 & 101.576 & 11.55 & 8.794 & 1.000 \\ 330 & 626 & 101.576 & 11.60 & 8.757 & 0.995 \\ 382 & 719 & 101.576 & 11.55 & 8.794 & 1.000 \\ 428 & 802 & 101.577 & 11.60 & 8.757 & 0.995 \\ 479 & 894 & 101.578 & 11.60 & 8.757 & 0.995 \\ 525 & 977 & 101.581 & 11.65 & 8.719 & 0.991 \\ 570 & 1058 & 101.583 & 11.60 & 8.757 & 0.996 \\ 620 & 1148 & 101.587 & 11.55 & 8.795 & 1.000 \\ 29 & 84 & 101.596 & 11.55 & 8.796 & 1.000\end{array}$

LOW TEMPERATURE TEST (Biomation Data)

$\begin{array}{rrrr}21 & 69 & 101.597 & 11.55 \\ 83 & 181 & 101.589 & 11.60 \\ 133 & 271 & 101.584 & 11.70 \\ 180 & 356 & 101.581 & 11.65 \\ 240 & 464 & 101.578 & 11.65 \\ 285 & 545 & 101.576 & 11.70 \\ 330 & 626 & 101.576 & 11.75 \\ 382 & 719 & 101.576 & 11.75 \\ 428 & 802 & 101.577 & 11.75 \\ 479 & 894 & 101.578 & 11.75 \\ 525 & 977 & 101.581 & 11.65 \\ 570 & 1058 & 101.583 & 11.75 \\ 620 & 1148 & 101.587 & 11.75\end{array}$

$\begin{array}{ll}8.796 & 1.000 \\ 8.758 & 0.996 \\ 8.682 & 0.987 \\ 8.719 & 0.991 \\ 8.719 & 0.991 \\ 8.682 & 0.987 \\ 8.645 & 0.983 \\ 8.645 & 0.983 \\ 8.645 & 0.983 \\ 8.645 & 0.983 \\ 8.719 & 0.991 \\ 8.645 & 0.983 \\ 8.646 & 0.983\end{array}$


TABLE II

Longitudinal Velocity Temperature Data for ROD \#2 Pitch/M2 Material

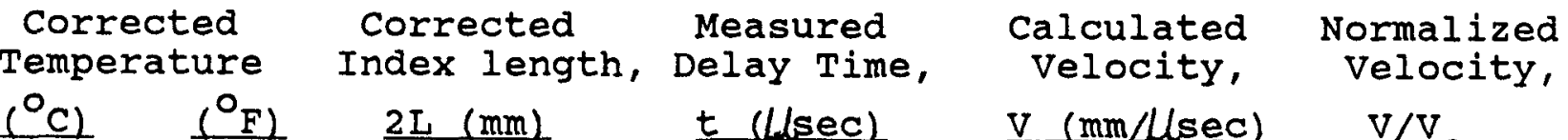

LOW TEMPERATURE TEST

$\begin{array}{rrrr}23 & 73 & 76.200 & 18.20 \\ 20 & 68 & 76.200 & 18.10 \\ 67 & 152 & 76.205 & 18.20 \\ 108 & 226 & 76.208 & 18.30 \\ 151 & 303 & 76.210 & 18.25 \\ 207 & 404 & 76.212 & 18.25 \\ 264 & 507 & 76.212 & 18.25 \\ 296 & 564 & 76.212 & 18.15 \\ 346 & 654 & 76.212 & 18.15 \\ 400 & 752 & 76.211 & 18.15 \\ 448 & 838 & 76.212 & 18.20 \\ 509 & 948 & 76.213 & 18.15 \\ 548 & 1018 & 76.214 & 18.10 \\ 603 & 1117 & 76.217 & 17.90 \\ 23 & 73 & 76.200 & 18.40 \\ 25 & 77 & 76.201 & 18.50\end{array}$

$\begin{array}{ll}4.187 & 1.000 \\ 4.210 & 1.006 \\ 4.187 & 1.000 \\ 4.164 & 0.995 \\ 4.176 & 0.997 \\ 4.176 & 0.997 \\ 4.176 & 0.997 \\ 4.199 & 1.003 \\ 4.199 & 1.003 \\ 4.199 & 1.003 \\ 4.187 & 1.000 \\ 4.199 & 1.003 \\ 4.211 & 1.006 \\ 4.258 & 1.017 \\ 4.141 & 0.989 \\ 4.119 & 0.984\end{array}$

LOW TEMPERATURE TEST (Biomation Data)

$\begin{array}{rrrr}25 & 77 & 76.201 & 18.20 \\ 151 & 303 & 76.210 & 18.20 \\ 207 & 404 & 76.212 & 18.20 \\ 264 & 507 & 76.212 & 18.10 \\ 296 & 564 & 76.212 & 18.10 \\ 346 & 654 & 76.212 & 18.20 \\ 400 & 752 & 76.211 & 18.20 \\ 448 & 838 & 76.212 & 18.20 \\ 509 & 948 & 76.213 & 18.20 \\ 548 & 1018 & 76.214 & 18.05 \\ 603 & 1117 & 76.217 & 18.00\end{array}$

$\begin{array}{ll}4.187 & 1.000 \\ 4.187 & 1.000 \\ 4.187 & 1.000 \\ 4.211 & 1.006 \\ 4.211 & 1.006 \\ 4.187 & 1.000 \\ 4.187 & 1.000 \\ 4.187 & 1.000 \\ 4.188 & 1.000 \\ 4.222 & 1.008 \\ 4.234 & 1.011\end{array}$

HIGH TEMPERATURE TEST

$\begin{array}{rrrrrr}25 & 77 & 76.201 & 18.20 & 4.187 & 1.000 \\ 25 & 77 & 76.201 & 18.25 & 4.175 & 0.997 \\ 704 & 1299 & 76.225 & 18.25 & 4.177 & 0.998 \\ 778 & 1432 & 76.233 & 18.30 & 4.166 & 0.995 \\ 945 & 1733 & 76.260 & 18.15 & 4.202 & 1.004 \\ 1085 & 1985 & 76.289 & 17.95 & 4.250 & 1.015 \\ 1270 & 2318 & 76.334 & 17.85 & 4.276 & 1.021 \\ 1346 & 2454 & 76.353 & 17.75 & 4.302 & 1.027\end{array}$


TABLE II continued

$\begin{array}{llll}1491 & 2715 & 76.388 & 17.60 \\ 1594 & 2901 & 76.411 & 17.30 \\ 1712 & 3113 & 76.435 & 16.95 \\ 1974 & 3585 & 76.480 & 16.65 \\ 2165 & 3929 & 76.513 & 16.45 \\ 2364 & 4287 & 76.567 & 17.15 \\ 2458 & 4456 & 76.607 & 17.25 \\ 2573 & 4663 & 76.677 & 17.45 \\ 2604 & 4719 & 76.701 & 17.50 \\ 2698 & 4888 & 76.790 & 17.85\end{array}$

4.340

1.037

4.417

1.055

4.509

1.077

4.593

1.097

4.651

1.111

4.465

4.441

4.394

1.066

1.061

4.383

1.050

4.302

1.047

1.027

HIGH TEMPERATURE TEST (Biomation Data)

$\begin{array}{rrrr}25 & 77 & 76.201 & 18.20 \\ 694 & 1281 & 76.224 & 18.05 \\ 778 & 1432 & 76.233 & 18.15 \\ 965 & 1768 & 76.264 & 18.05 \\ 1105 & 2021 & 76.294 & 17.90 \\ 1270 & 2318 & 76.334 & 17.80 \\ 1346 & 2452 & 76.353 & 17.65 \\ 1501 & 2733 & 76.390 & 17.40 \\ 1609 & 2928 & 76.414 & 17.15 \\ 1747 & 3176 & 76.442 & 16.85 \\ 1974 & 3585 & 76.480 & 16.70 \\ 2195 & 3983 & 76.520 & 16.60 \\ 2364 & 4287 & 76.567 & 17.10 \\ 2458 & 4456 & 76.607 & 17.15 \\ 2604 & 4719 & 76.701 & 17.50\end{array}$

4.187

1.000

4.223

1.009

4.200

1.003

4.225

1.009

4.262

1.018

4.288

1.024

4.326

1.033

4.390

1.049

4.456

1.064

4.537

1.084

4.580

1.094

4.610

1.101

4.478

1.069

4.467

1.067

4.383

1.047 
TABLE III

Longitudinal Velocity Temperature Data for ROD \#3 Pitch Parent Material

\begin{tabular}{|c|c|c|c|c|}
\hline $\begin{array}{l}\text { Corrected } \\
\text { Temperature }\end{array}$ & $\begin{array}{l}\text { Corrected } \\
\text { Index length, }\end{array}$ & $\begin{array}{c}\text { Measured } \\
\text { Delay Time, }\end{array}$ & $\begin{array}{c}\text { Calculated } \\
\text { Velocity, }\end{array}$ & $\begin{array}{c}\text { Normalized } \\
\text { Velocity, }\end{array}$ \\
\hline$\left({ }^{\circ} \mathrm{C}\right) \quad\left({ }^{\circ} \mathrm{F}\right)$ & $\underline{2 L}(\mathrm{~mm})$ & $t\left(\mu_{\mathrm{sec}}\right)$ & $\mathrm{V}(\mathrm{mm} / / \mathrm{sec})$ & $\mathrm{V} / \mathrm{v}_{0}$ \\
\hline
\end{tabular}

LOW TEMPERATURE TEST

$\begin{array}{rrrr}25 & 77 & 101.597 & 10.55 \\ 72 & 161 & 101.591 & 10.55 \\ 120 & 248 & 101.586 & 10.60 \\ 159 & 318 & 101.582 & 10.60 \\ 203 & 397 & 101.579 & 10.45 \\ 253 & 487 & 101.577 & 10.35 \\ 303 & 577 & 101.576 & 10.30 \\ 348 & 658 & 101.576 & 10.25 \\ 395 & 743 & 101.576 & 10.25 \\ 433 & 811 & 101.577 & 10.20 \\ 496 & 924 & 101.579 & 10.20 \\ 550 & 1022 & 101.582 & 10.15 \\ 606 & 1122 & 101.586 & 10.15 \\ 660 & 1220 & 101.590 & 10.20 \\ 23 & 73 & 101.597 & 10.55\end{array}$

$\begin{array}{rr}9.630 & 1.000 \\ 9.629 & 1.000 \\ 9.584 & 0.995 \\ 9.583 & 0.995 \\ 9.721 & 1.009 \\ 9.814 & 1.019 \\ 9.862 & 1.024 \\ 9.910 & 1.029 \\ 9.910 & 1.029 \\ 9.959 & 1.034 \\ 9.959 & 1.034 \\ 10.008 & 1.039 \\ 10.008 & 1.039 \\ 9.96 & 1.034 \\ 9.63 & 1.000\end{array}$

LOW TEMPERATURE TEST (Biomation Data)

$\begin{array}{rrrrrr}25 & 77 & 101.597 & 10.55 & 9.630 & 1.000 \\ 72 & 161 & 101.591 & 10.55 & 9.629 & 1.000 \\ 120 & 248 & 101.586 & 10.45 & 9.721 & 1.009 \\ 159 & 318 & 101.582 & 10.50 & 9.675 & 1.005 \\ 203 & 397 & 101.579 & 10.40 & 9.767 & 1.014 \\ 253 & 487 & 101.577 & 10.30 & 9.862 & 1.024 \\ 303 & 577 & 101.576 & 10.30 & 9.862 & 1.024 \\ 348 & 658 & 101.576 & 10.30 & 9.862 & 1.024 \\ 395 & 743 & 101.576 & 10.20 & 9.958 & 1.034 \\ 433 & 811 & 101.577 & 10.20 & 9.959 & 1.034 \\ 497 & 926 & 101.579 & 10.15 & 10.008 & 1.039 \\ 551 & 1023 & 101.582 & 10.20 & 9.959 & 1.034 \\ 606 & 1122 & 101.586 & 10.10 & 10.058 & 1.044 \\ 660 & 1220 & 101.590 & 10.20 & 9.960 & 1.034\end{array}$

HIGH TEMPERATURE TEST

$\begin{array}{rrrrrr}25 & 77 & 101.597 & 10.55 & 9.630 & 1.000 \\ 693 & 1279 & 101.593 & 10.30 & 9.863 & 1.024 \\ 704 & 1299 & 101.594 & 10.35 & 9.816 & 1.019 \\ 799 & 1470 & 101.604 & 10.35 & 9.817 & 1.019 \\ 850 & 1562 & 101.610 & 10.25 & 9.913 & 1.029\end{array}$


TABLE III continued

$\begin{array}{rrrrrr}856 & 1572 & 101.611 & 10.35 & 9.817 & 1.019 \\ 904 & 1659 & 101.617 & 10.30 & 9.866 & 1.024 \\ 997 & 1826 & 101.630 & 10.25 & 9.915 & 1.030 \\ 1044 & 1911 & 101.637 & 10.25 & 9.916 & 1.030 \\ 1076 & 1968 & 101.642 & 10.15 & 10.014 & 1.040 \\ 1301 & 2373 & 101.679 & 10.20 & 9.968 & 1.035 \\ 1502 & 2735 & 101.716 & 10.15 & 10.021 & 1.041 \\ 1584 & 2883 & 101.732 & 10.25 & 9.925 & 1.031 \\ 1703 & 3097 & 101.757 & 10.30 & 9.879 & 1.026 \\ 1928 & 3502 & 101.809 & 10.30 & 9.884 & 1.026 \\ 2049 & 3720 & 101.840 & 10.55 & 9.653 & 1.002 \\ 2238 & 4060 & 101.896 & 10.55 & 9.658 & 1.003 \\ 2359 & 4278 & 101.936 & 10.30 & 9.897 & 1.028 \\ 2500 & 4532 & 101.990 & 10.25 & 9.950 & 1.033 \\ 2636 & 4776 & 102.050 & 10.15 & 10.054 & 1.044 \\ 2636 & 4776 & 102.050 & 10.10 & 10.104 & 1.049 \\ 2719 & 4926 & 102.091 & 10.15 & 10.058 & 1.044 \\ 2833 & 5131 & 102.154 & 10.10 & 10.114 & 1.050 \\ 3009 & 5448 & 102.267 & 9.90 & 10.330 & 1.073 \\ 3061 & 5541 & 102.305 & 9.95 & 10.282 & 1.068 \\ 3081 & 5577 & 102.320 & 9.90 & 10.335 & 1.073\end{array}$

HIGH TEMPERATURE TEST (Biomation Data)

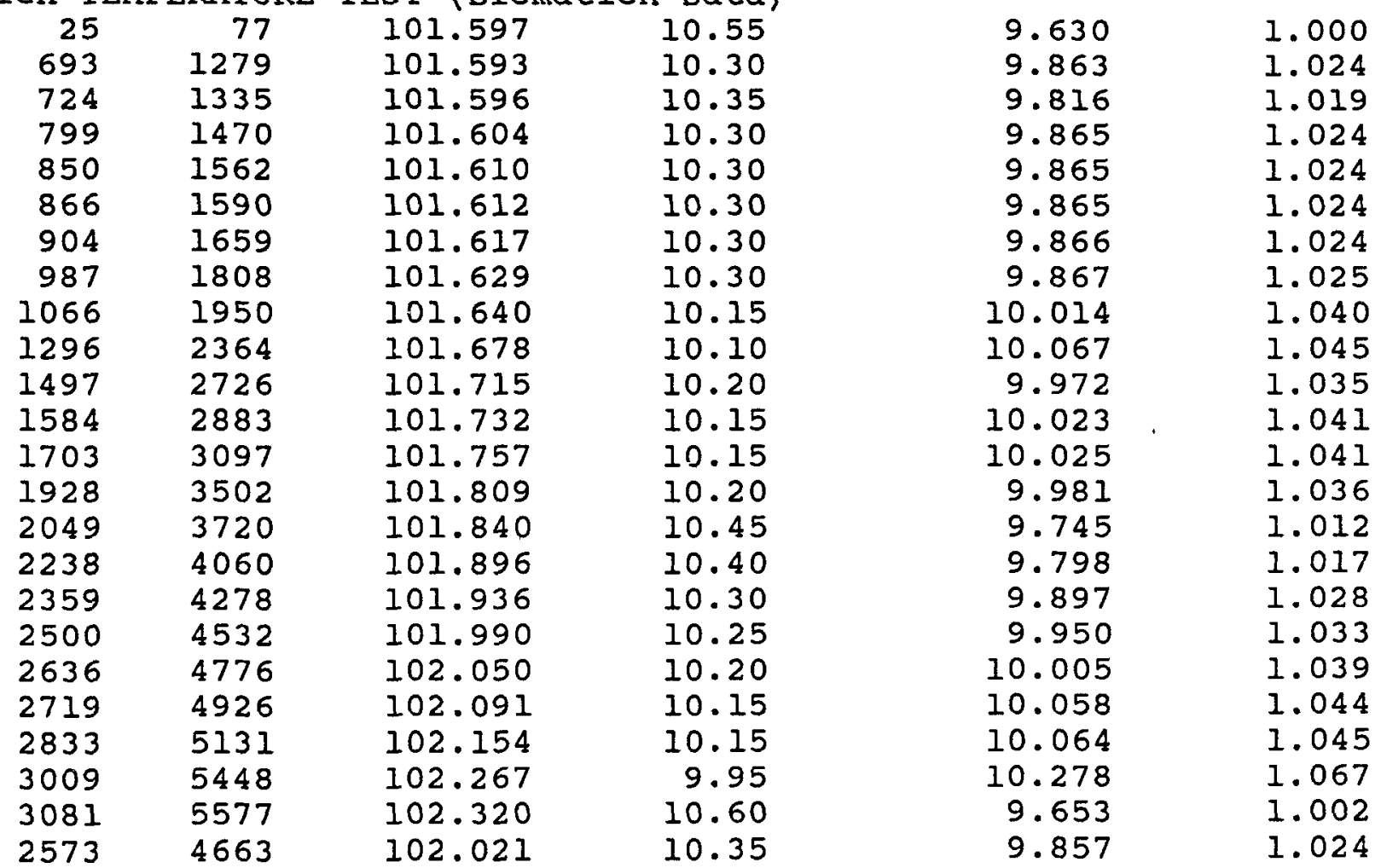


$$
\text { . }
$$ 


\section{APPENDIX A}

ROD \# I PITCH PARENT MATERIAL WAVEFORMS FOR; THE INITIAL ROD VELOCITY, THE NOTCH MACHINING PROCESS, LOW TEMPERATURE TEST \# 1 , THE HIGH TEMPERATURE TEST, AND LOW TEMPERATURE TEST \#2 


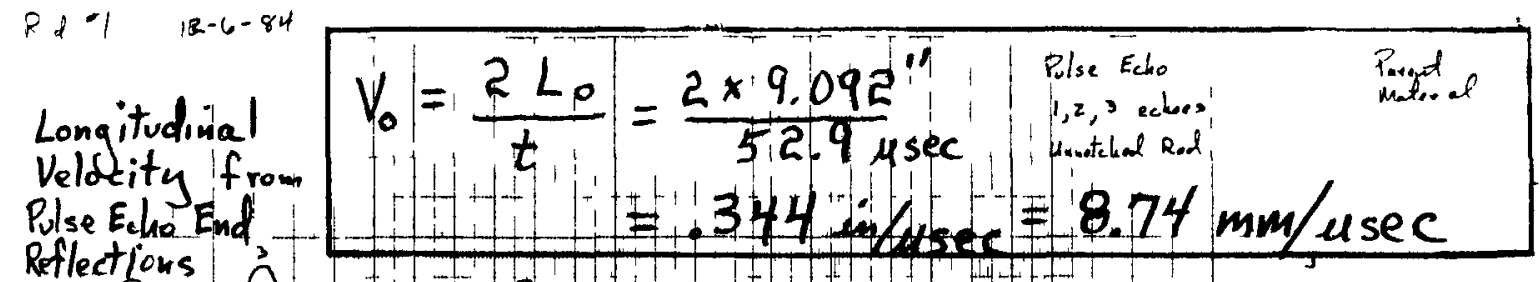

(2) Retlections $\int^{3}$

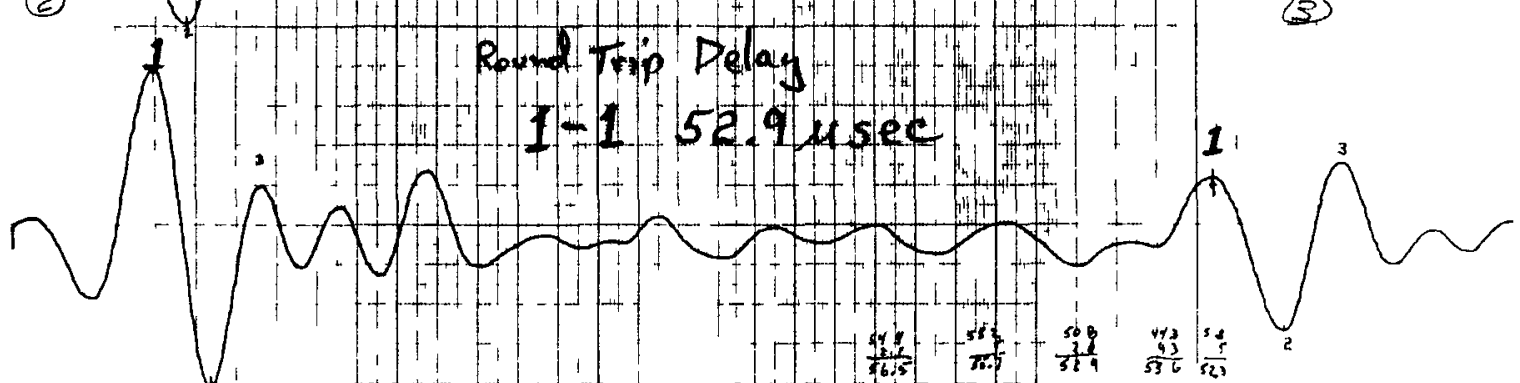

Ist Rod End $\frac{1}{P E}$. $200 \mathrm{Mtz}$ (2nd fod End

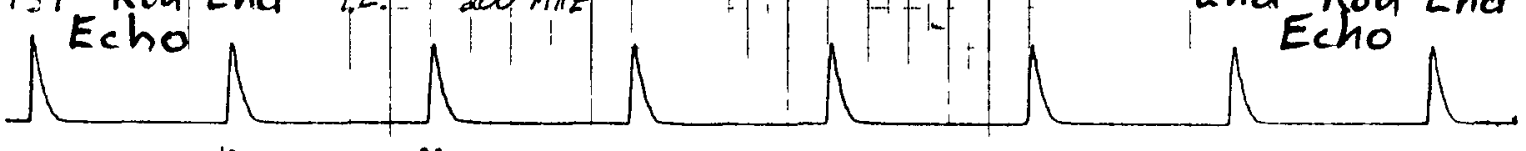

$20 \ldots$
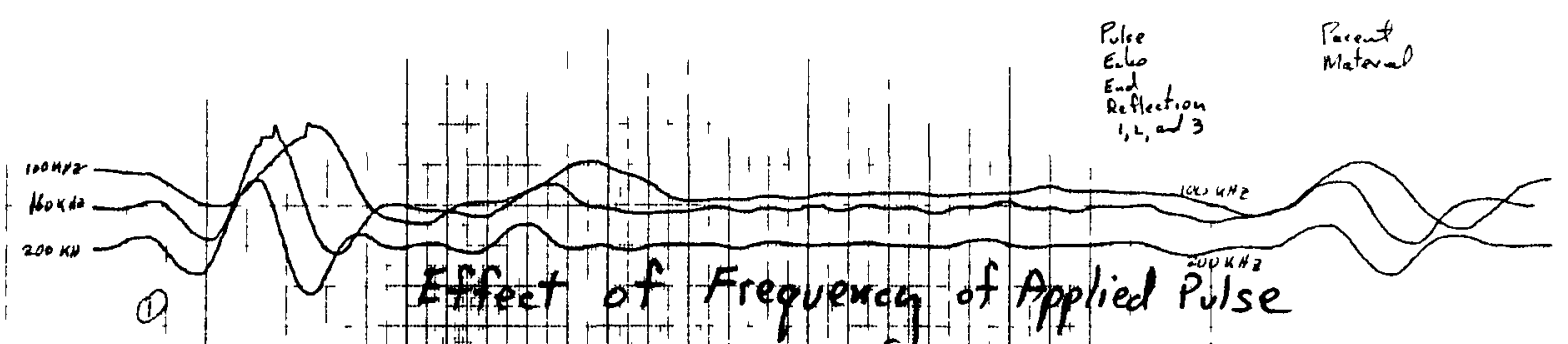

(1) Dofet of frequench of Applied Pulse

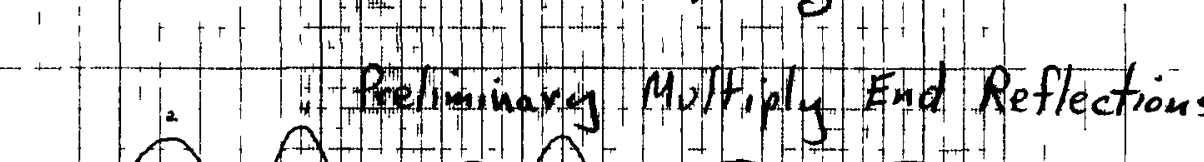

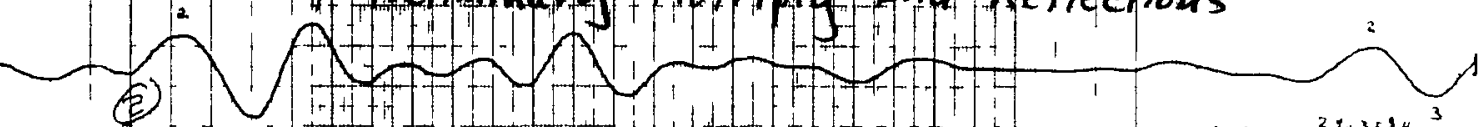

,- and End Echat t

3id End Echo

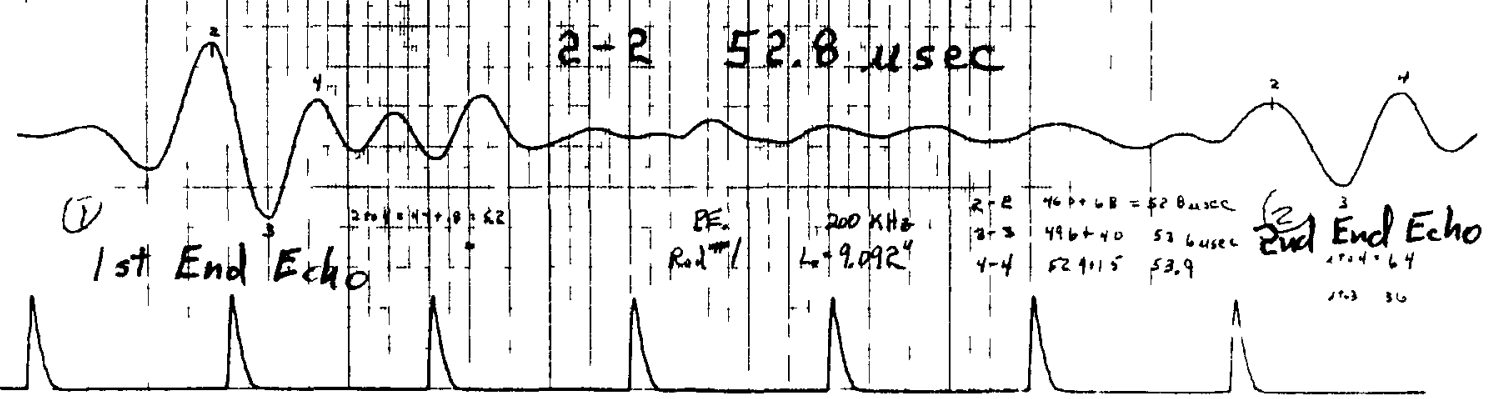

Pulse Fcho Waveforms of Unnotched ROD \#I 


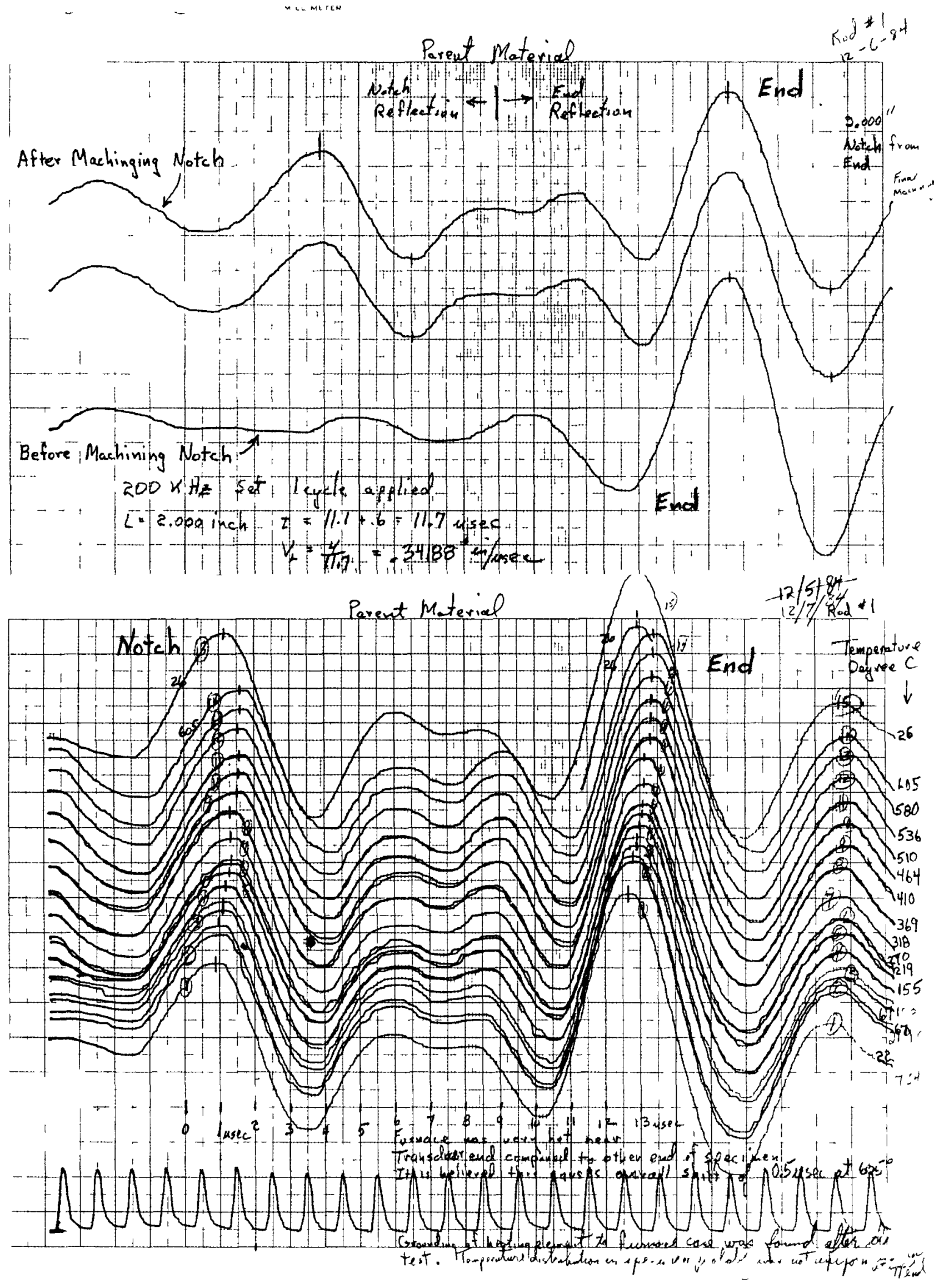

Pulse Echo Waveforms of Notch Machining Process and Low Temperature Test \#l for ROD \#1 
cot 121084
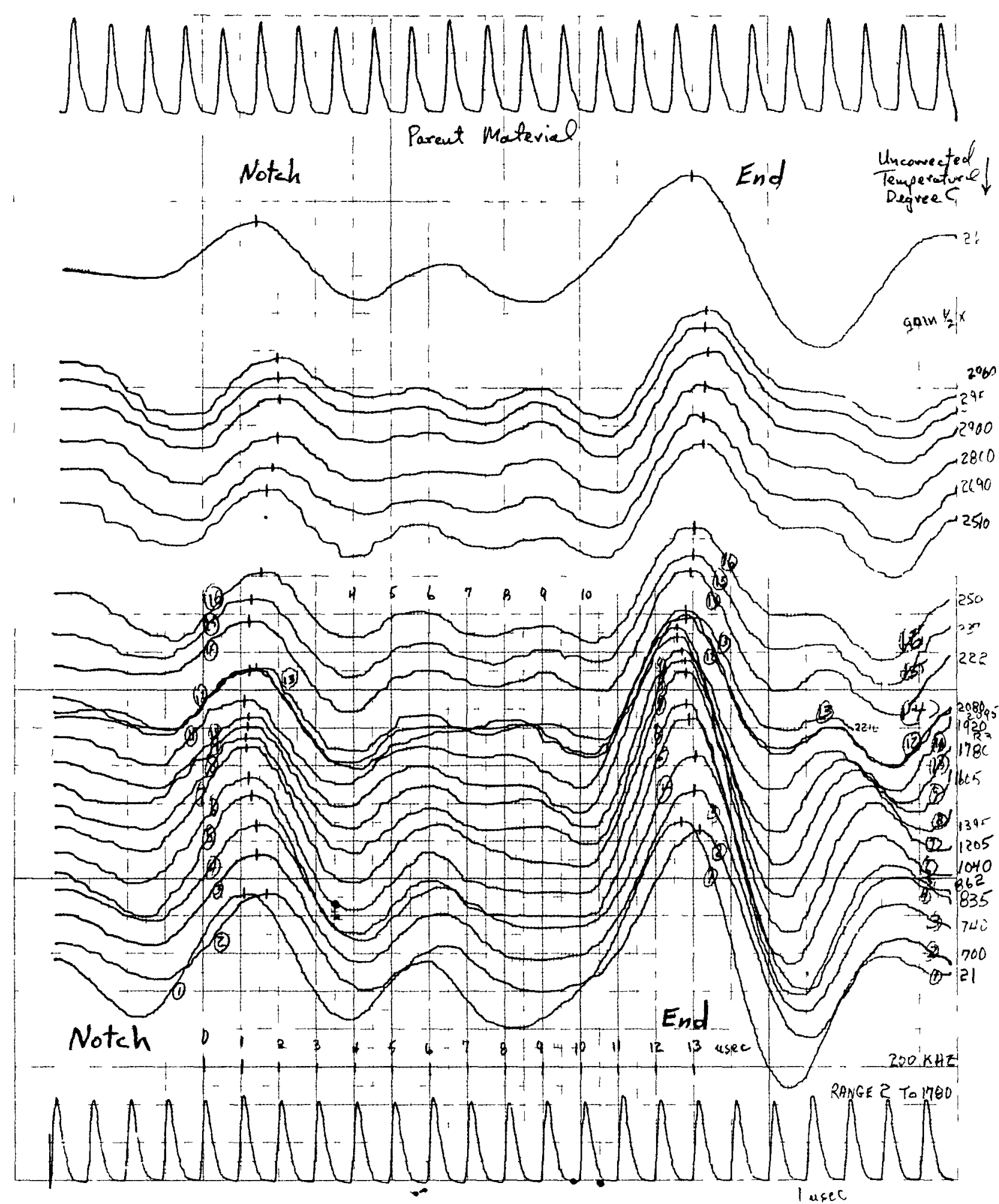

Pulse Echo Waveforms of High Temperature Test of ROD \#I 


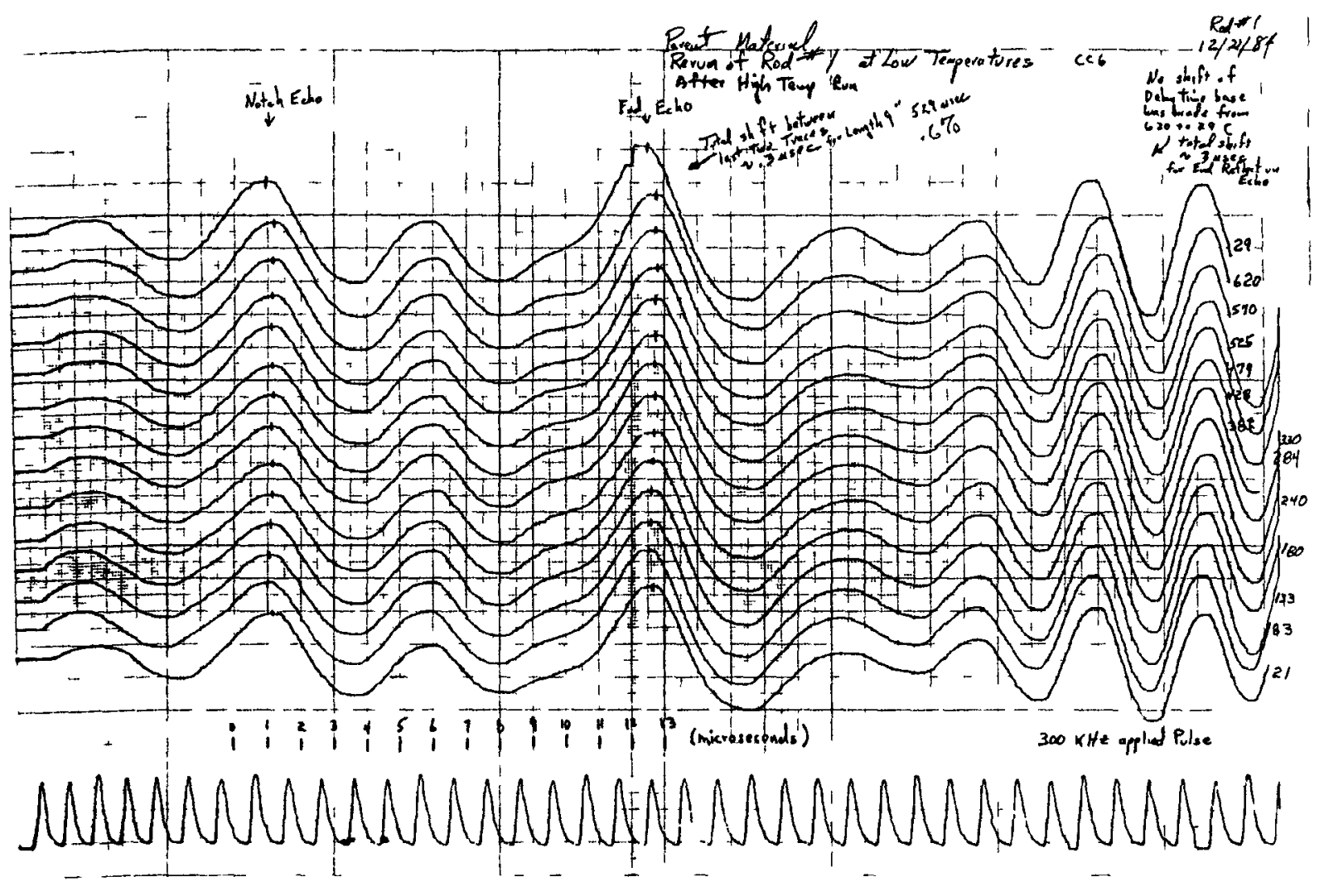

Pulse Echo Waveforms of Low Temperature Test \#2 of RCD \#1 
APPENDIX B

ROD \#2 PITCH/M2 MATERIAL WAVEFORMS FOR;

THE INITIAL ROD VELOCITY, THE NOTCH MACHINING PROCESS, THE LOW TEMPERATURE TEST, AND THE HIGH TEMPERATURE TEST. 


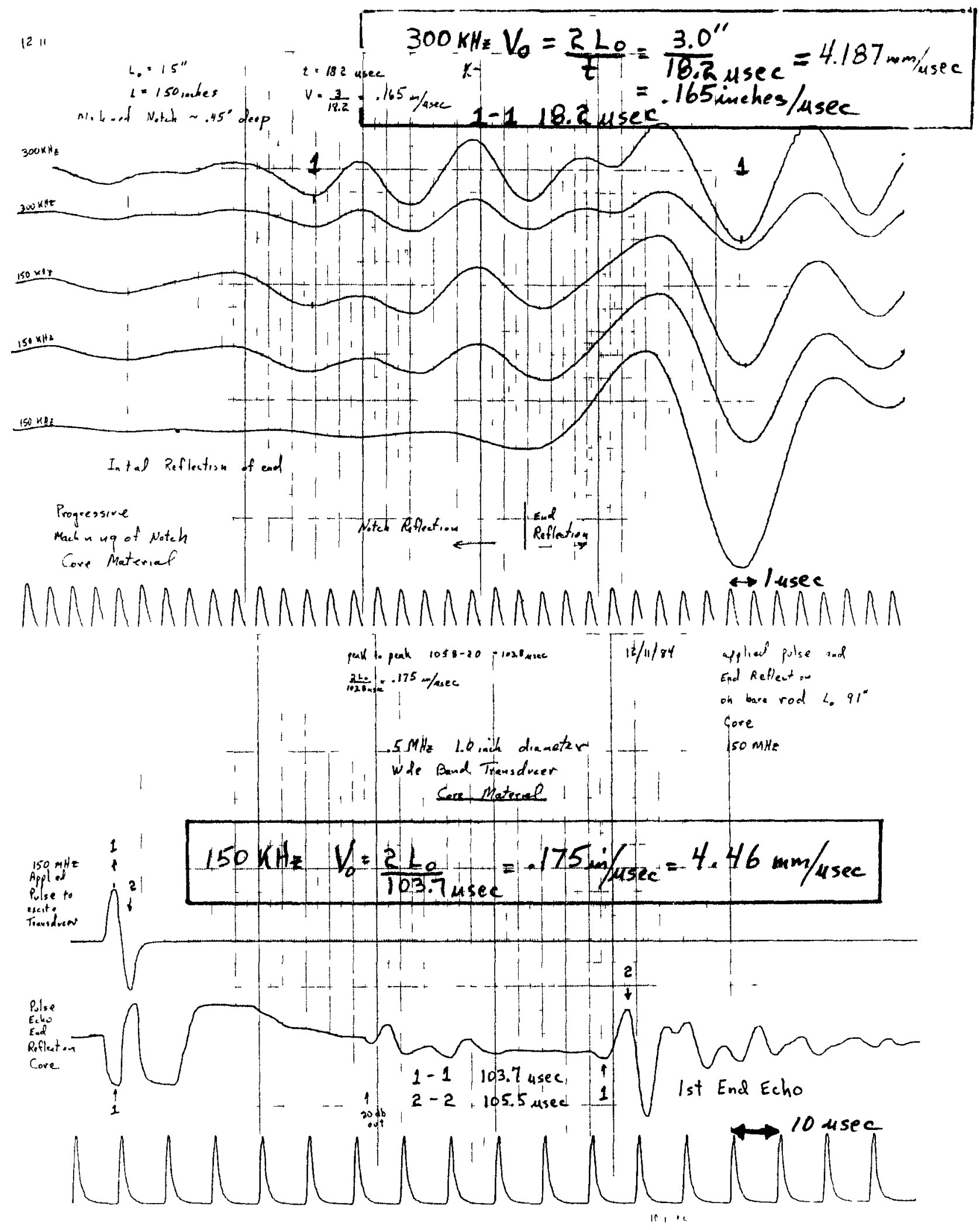

Pulse Echo Waveforms of Unnotched ROD \#2 and Notch Vachining Process 


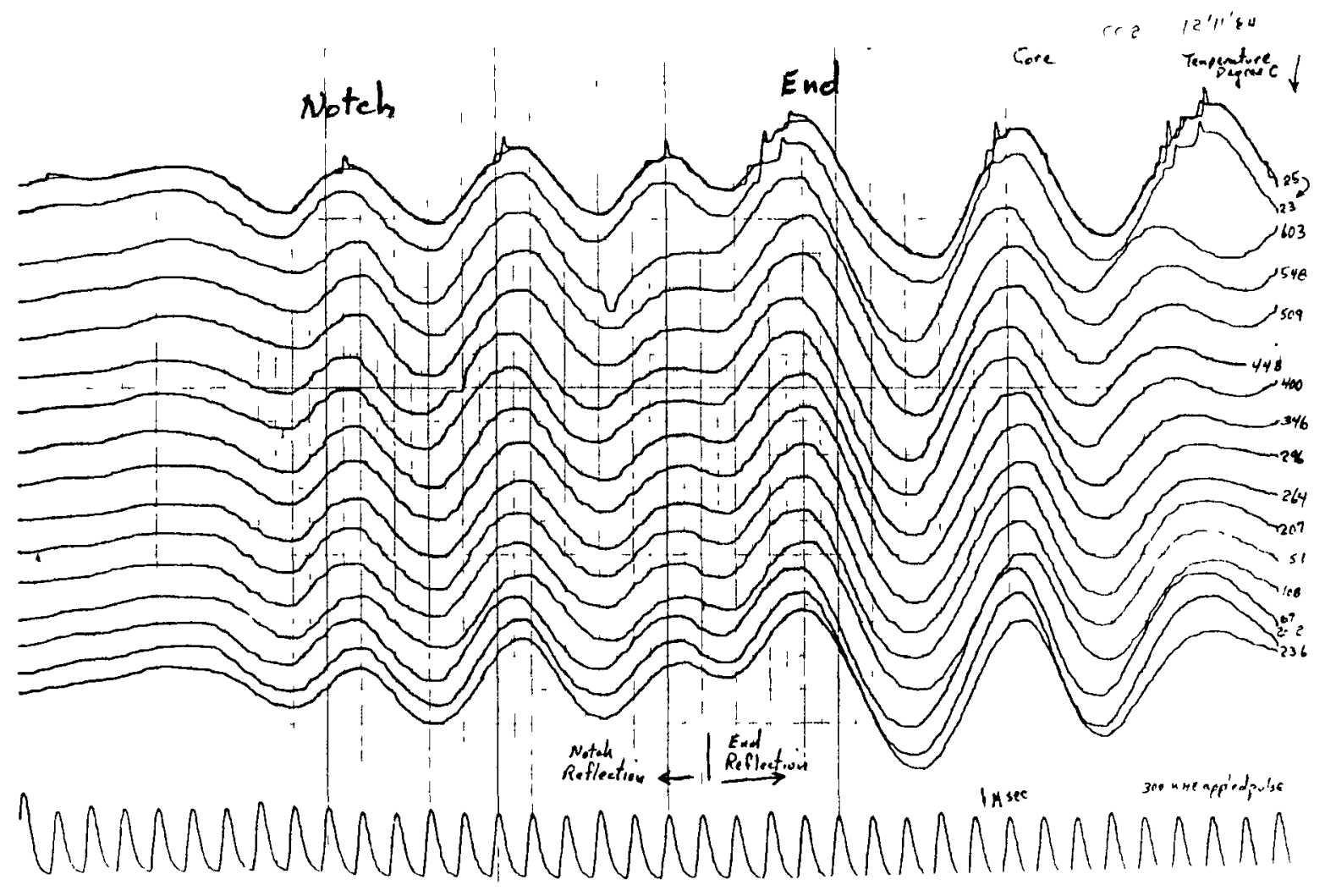

Pulse Echo Waveforms of Iow Temperature Test of ROD \#2 


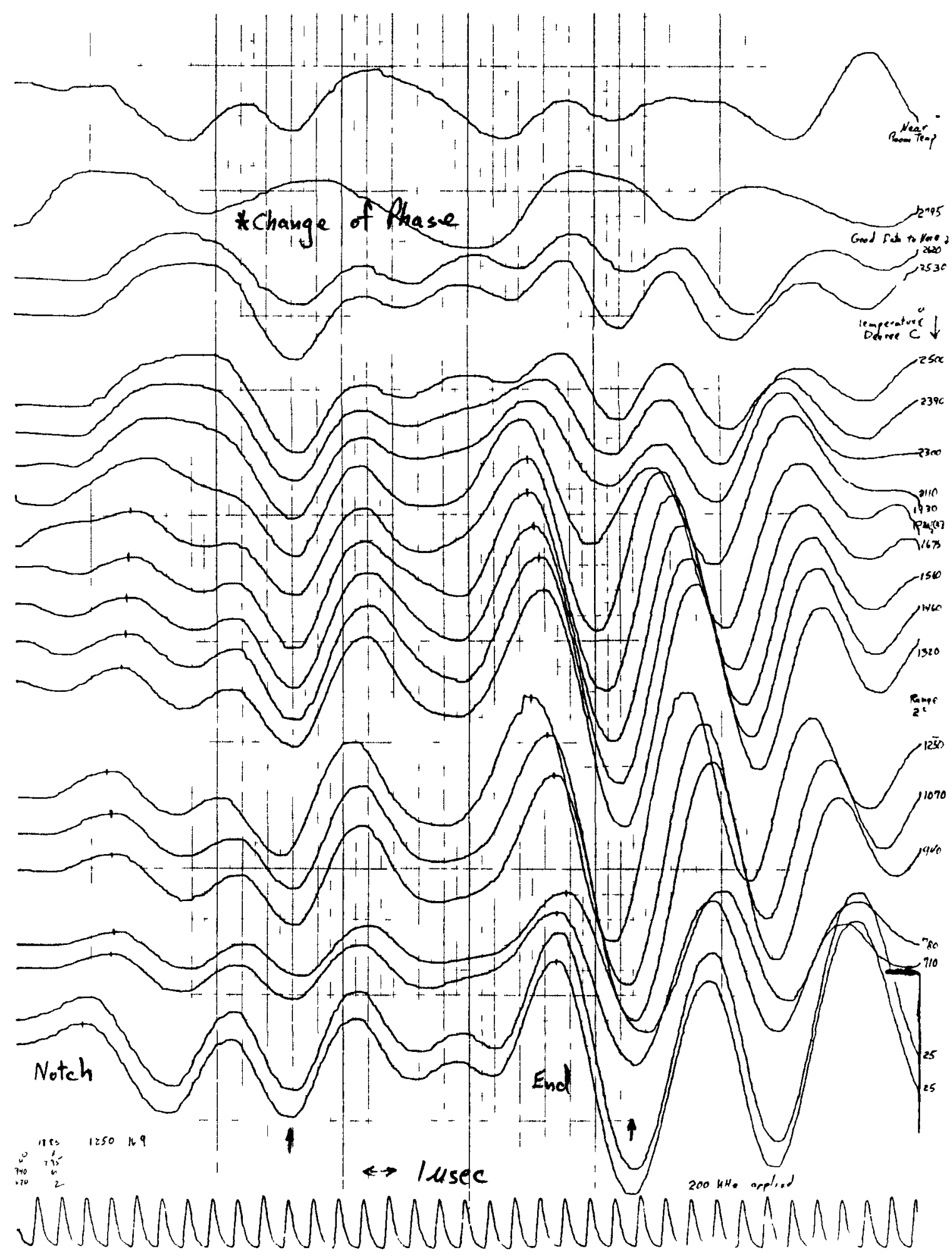

Pulse Echo Waveforms of High Temperature Test of ROD \#2 


\section{APPENDIX C}

ROD \#3 PITCH PARENT MATERIAL WAVEFORMS FOR;

THE INITIAL ROD VELOCITY, THE NOTCH MACHINING PROCESS, THE LOW TEMPERATURE TEST, AND THE HIGH TEMPERATURE TEST. 


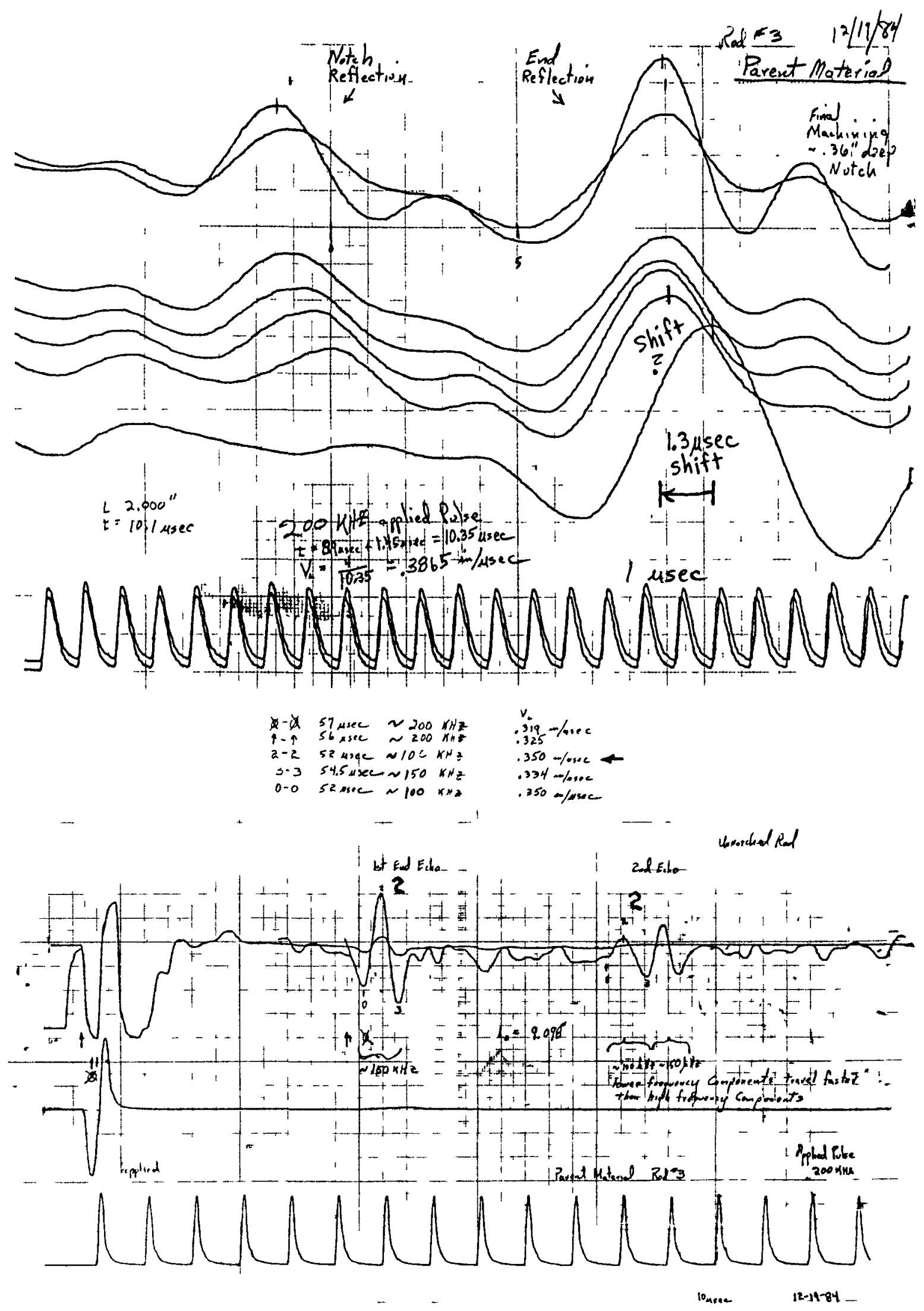

Pulse Echo Waveforms of Unnotched ROD \#3 and Notch Machining Process 


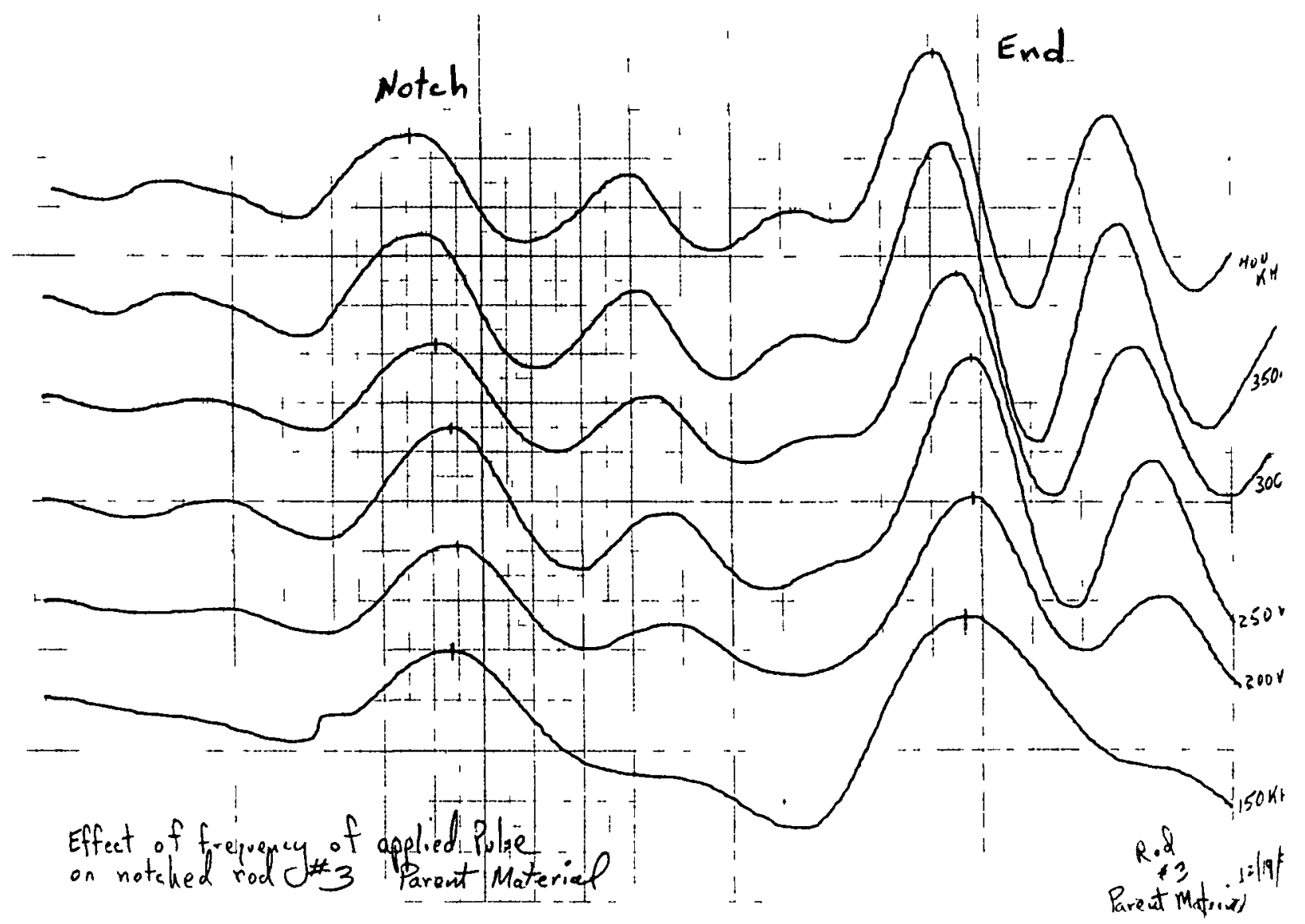

Pulse Echo Waveforms of Notched ROD \#3 from $150 \mathrm{KHz}$ to $400 \mathrm{KHz}$ Applied Pulse 


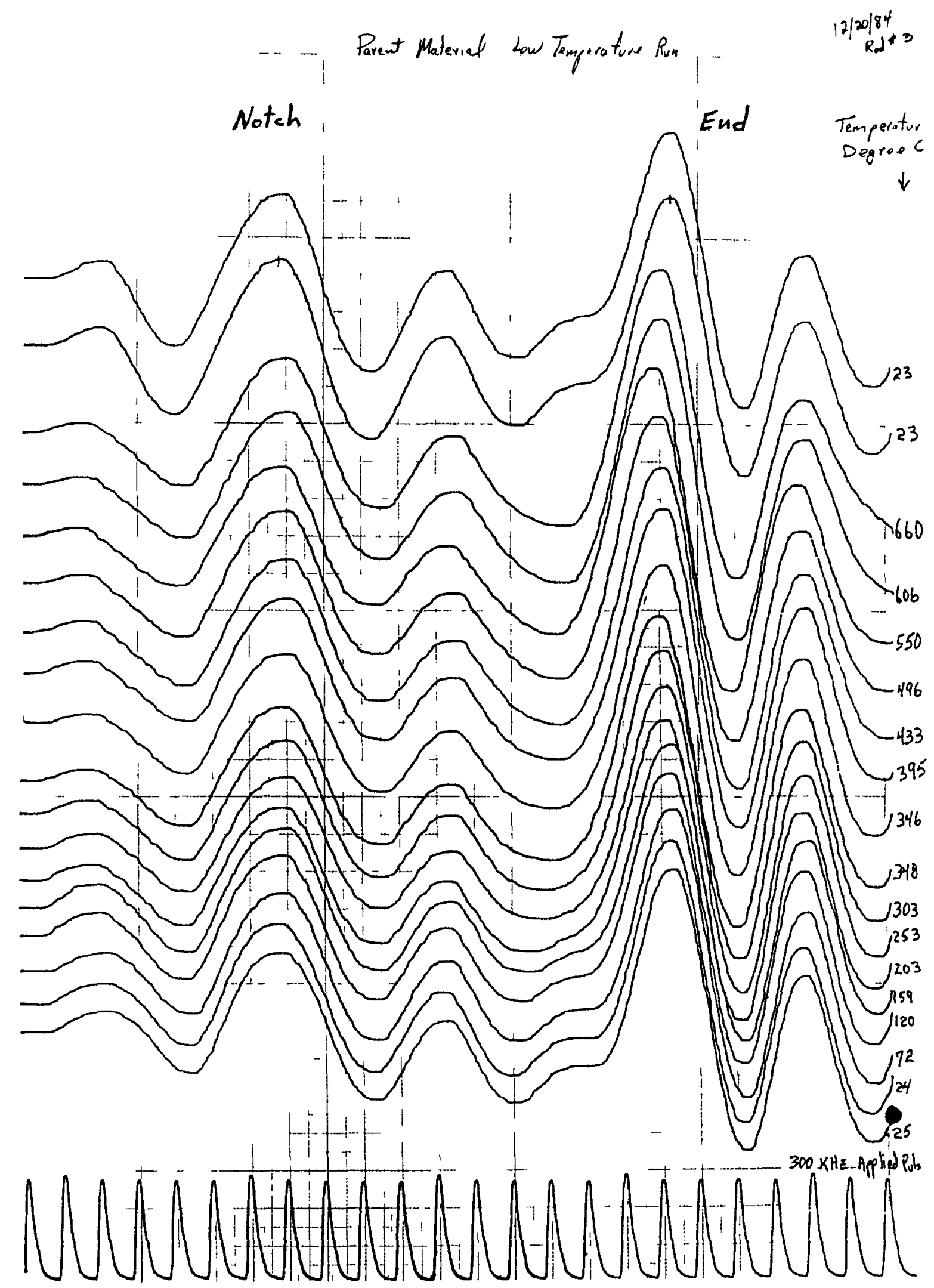

Pulse Echo Waveforms of Low Temperature Test of ROD \#3 


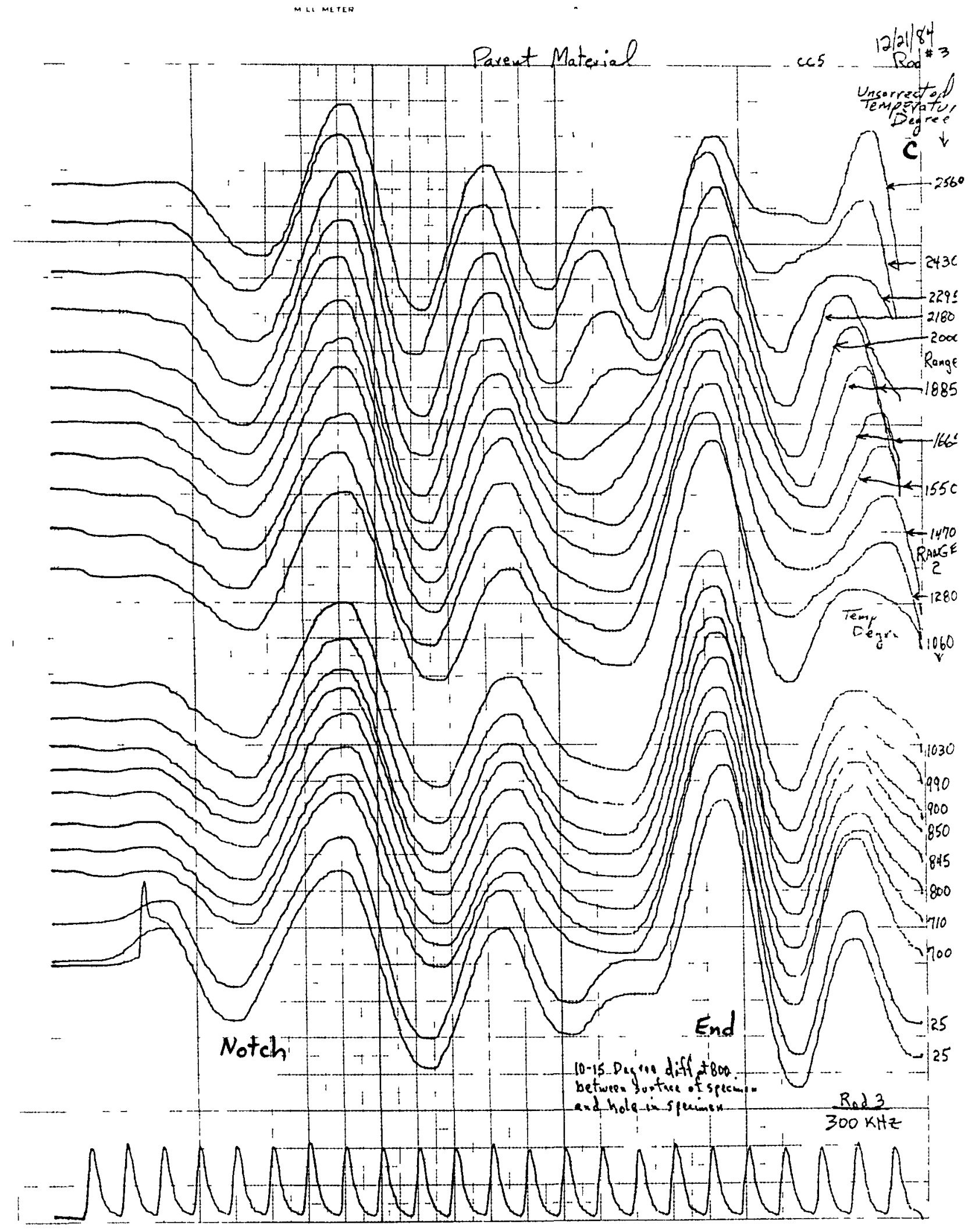

Pulse Echo Waveforms of High Temperature Test of ROD \#3 


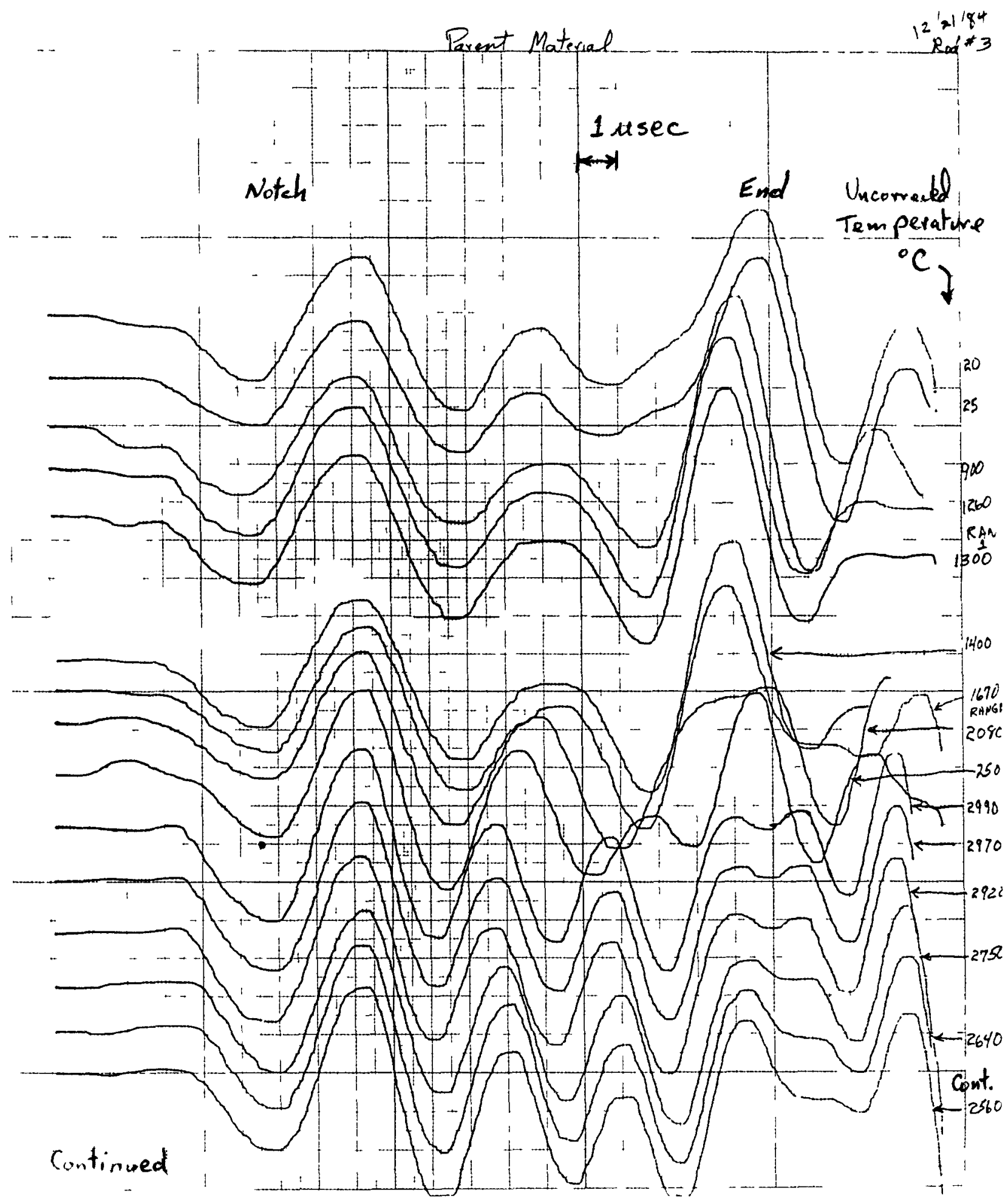

Pulse Echo Waveforms of High Temperature Test of ROD \#3 


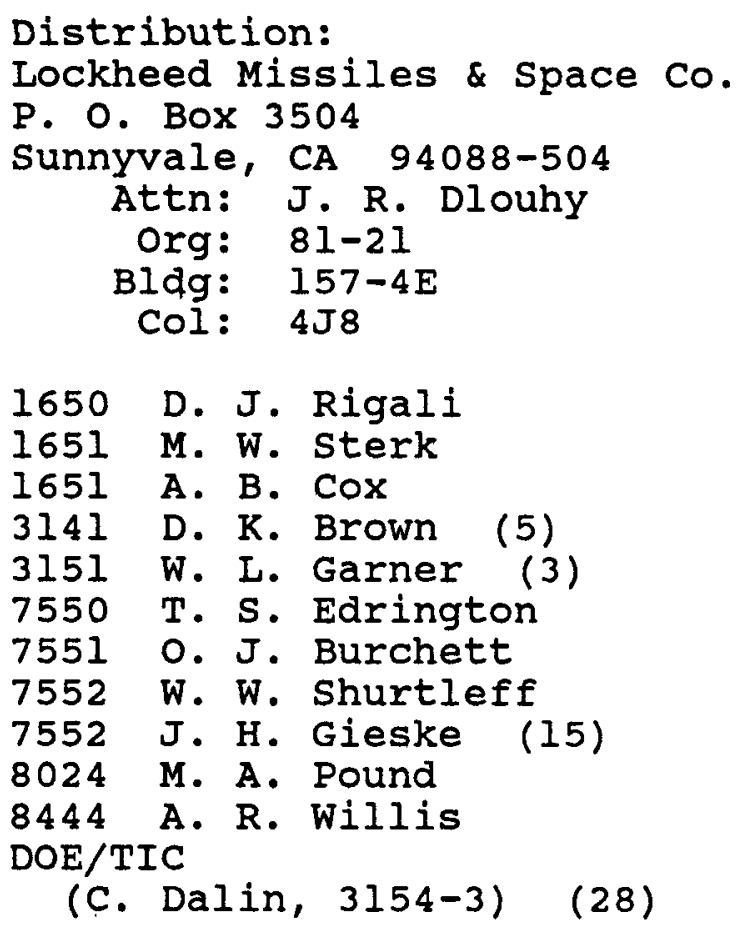

